\title{
WestVirginiaUniversity
}

THE RESEARCH REPOSITORY @ WVU

Graduate Theses, Dissertations, and Problem Reports

2018

\section{Beef Cattle Effluent Treatment in a Denitrifying Bioreactor.}

\author{
Bethani Chambers
}

Follow this and additional works at: https://researchrepository.wvu.edu/etd

\section{Recommended Citation}

Chambers, Bethani, "Beef Cattle Effluent Treatment in a Denitrifying Bioreactor." (2018). Graduate Theses, Dissertations, and Problem Reports. 8206.

https://researchrepository.wvu.edu/etd/8206

This Thesis is protected by copyright and/or related rights. It has been brought to you by the The Research Repository @ WVU with permission from the rights-holder(s). You are free to use this Thesis in any way that is permitted by the copyright and related rights legislation that applies to your use. For other uses you must obtain permission from the rights-holder(s) directly, unless additional rights are indicated by a Creative Commons license in the record and/ or on the work itself. This Thesis has been accepted for inclusion in WVU Graduate Theses, Dissertations, and Problem Reports collection by an authorized administrator of The Research Repository @ WVU. For more information, please contact researchrepository@mail.wvu.edu. 


\title{
Beef Cattle Effluent Treatment in a Denitrifying Bioreactor \\ Bethani Chambers
}

\author{
Thesis submitted to the \\ Davis College of Agriculture, Natural Resources, and Design \\ At West Virginia University \\ in partial fulfillment of the requirements for the degree
}

Masters of Science

in

Agronomy

Louis M. McDonald, Ph.D., Chair

Tom J. Basden, M.S

Ember M. Morrissey, Ph.D.

Division of Plant and Soil Sciences

Morgantown, West Virginia

2018

Keywords: Denitrifying bioreactor, nitrate, phosphorus, woodchips, denitrification, biochar

Copyright 2018 Bethani Chambers 


\section{Abstract \\ Beef Cattle Effluent Treatment in a Denitrifying Bioreactor}

\section{Bethani Chambers}

Excess nutrient runoff, nitrates and phosphates, has led to the development of algal blooms and hypoxic zones worldwide. Based on a report from the Chesapeake Bay Foundation nearly half of all nutrient sources originate from agricultural production with a quarter of this resulting from improper management of manures. This project focuses on a novel adaption of a denitrifying bioreactor, which has demonstrated removals of agricultural nutrients, which may have implications on the treatment of manure nutrients. These subsurface bioreactors work by providing a substrate, usually wood based, to act as a carbon source to support denitrifying bacteria which in turn systematically convert nitrate to nitrogen gas via microbial denitrification. In recent years biochar products have shown some effect on the leaching of soil nutrients and may aid in capturing nutrients in these bioreactors. For this study, a hardwood mix was chosen as the carbon substrate with 2 treatments of biochar additions at $10 \%$ and $50 \%$ by weight. Samples times of $0,1,4,8,12,16$, and 24 hours were collected then evaluated for total Kjeldahl nitrogen, nitrate, $\mathrm{pH}, \mathrm{EC}$, as well as, total and inorganic phosphorus, and calcium. Overall, nitrate concentration did not decrease over time, and there was no significant reduction in phosphorus. Based on the data collect, additional testing may need to be done in order to determine the effectiveness of a denitrifying bioreactor in treating manure sourced nutrients. 


\section{Acknowledgments}

I would like to thank all those who have helped me to this point in my life. Parents, professors, colleges, advisors, friends there are too many to name. From raising me to be the person I am, to helping me in troubled times or when I needed assistance, to carrying heavy boxes or getting things off the tall shelves for me your assistance was not forgotten and not without thanks. To quote the late Theodore Roosevelt, "Do what you can, with what you have, where you are" holds true to my experience. Through the struggles and ups and down, there always seemed a lesson or opportunity waiting at the end, thanks to those who offered their support. All this work and effort is dedicated to them, to who I could never thank enough. Thank you. 


\section{Table of Contents}

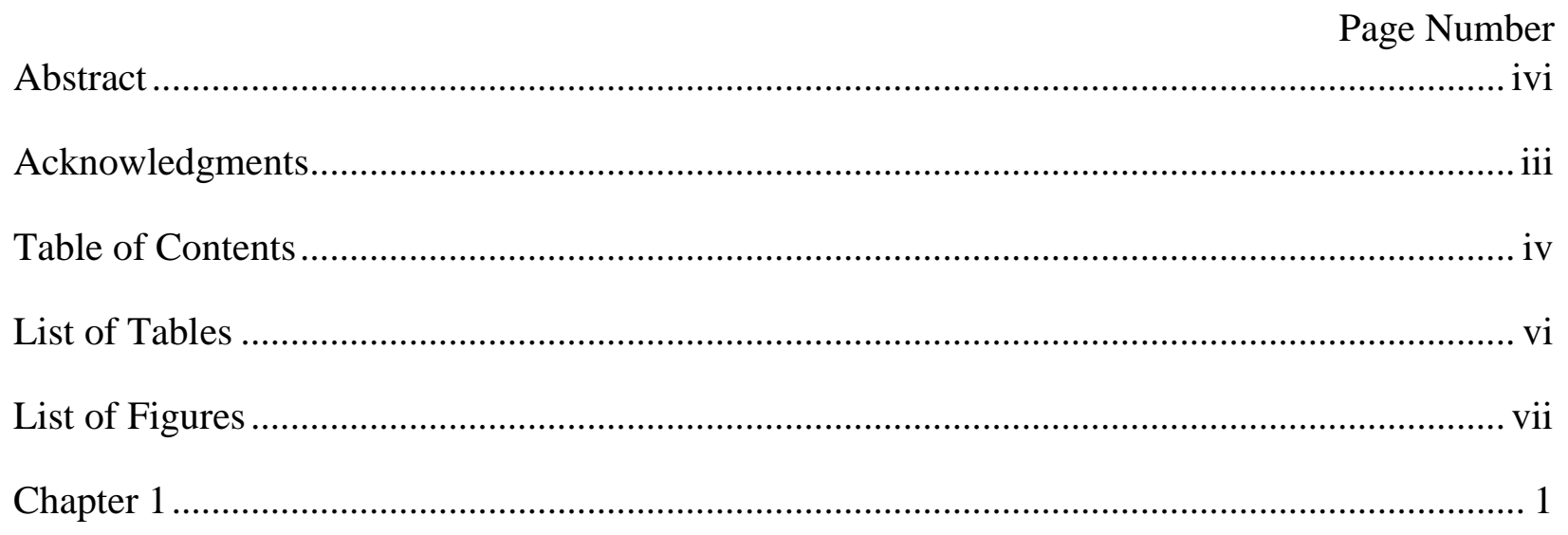

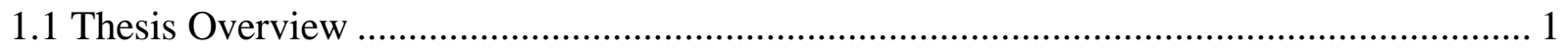

1.3 Nitrogen and Phosphorus in the Environment ................................................................. 3

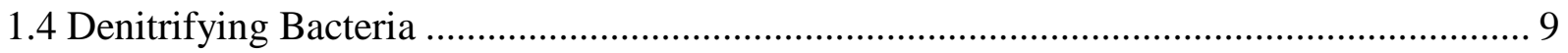

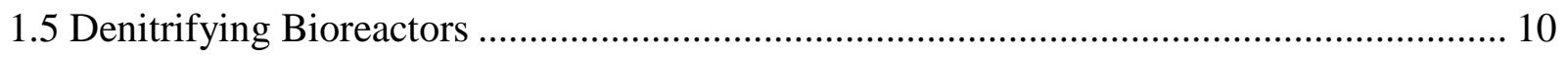

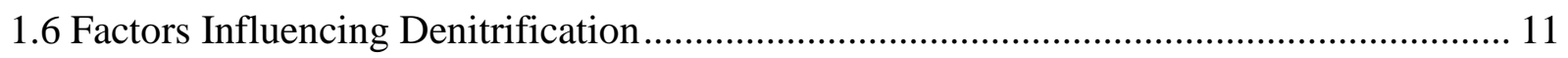

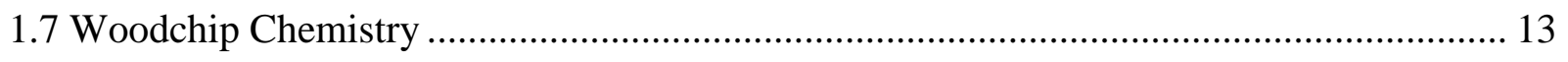

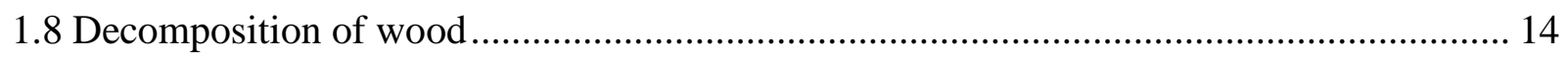

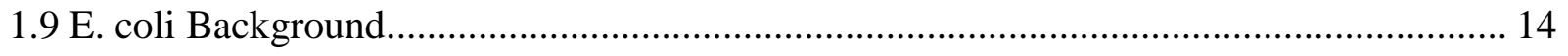

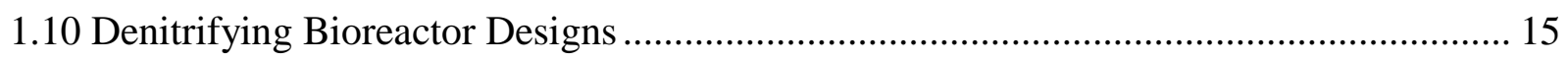

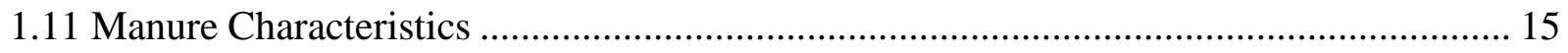

1.12 Relevance

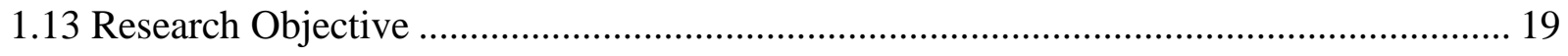

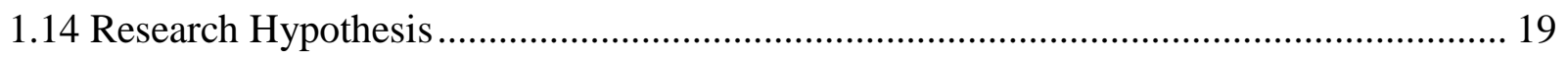

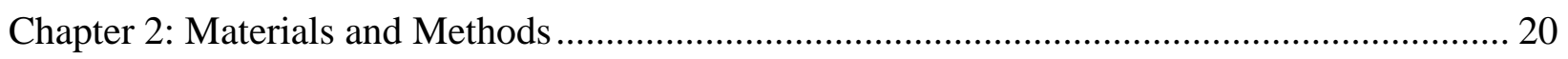

2.1 Organic Carbon-Based Media....................................................................................... 20

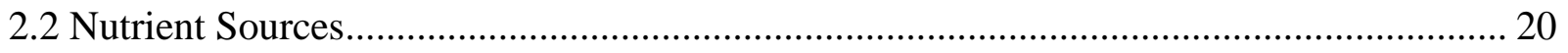

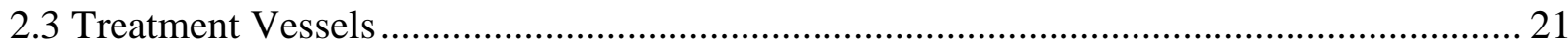




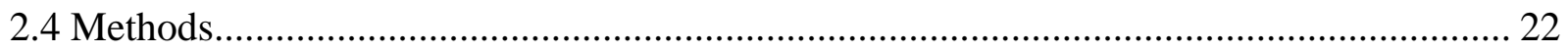

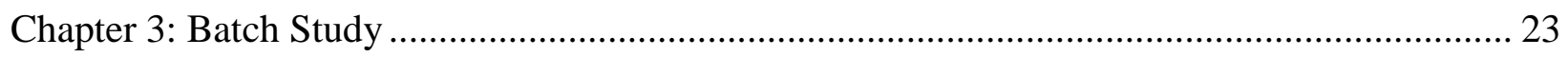

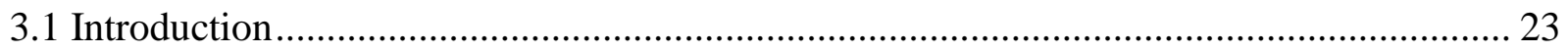

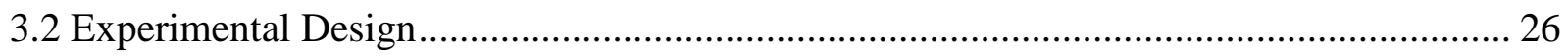

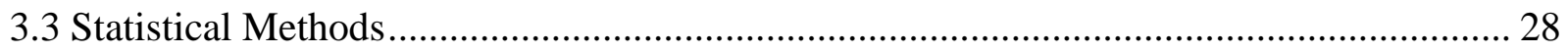

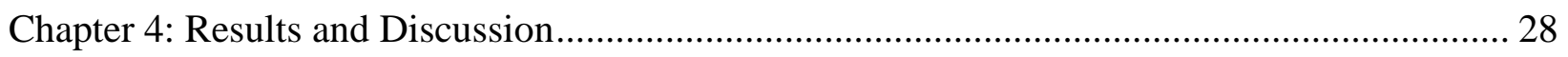

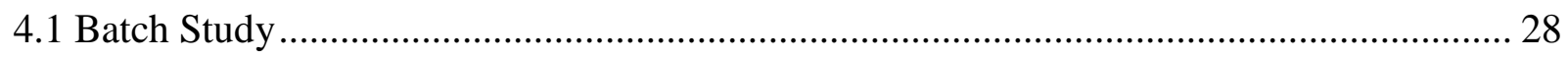

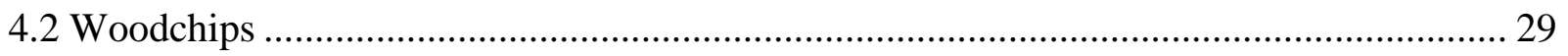

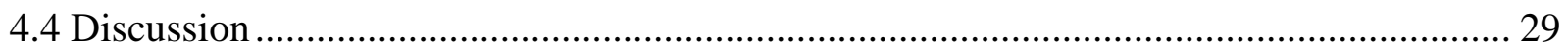

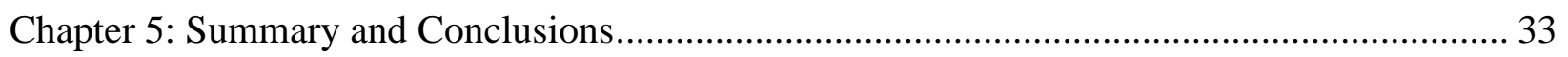

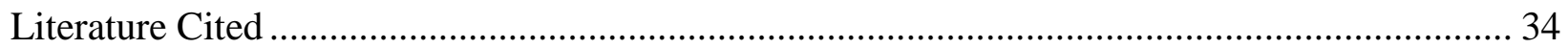

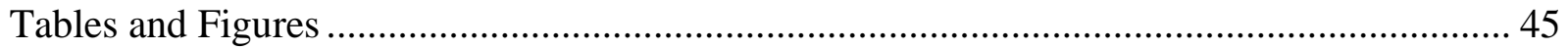

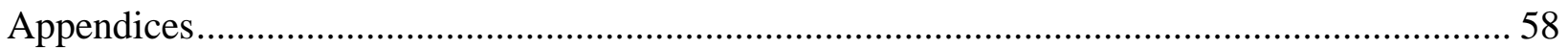

Appendix 1: Preliminary Study: Assessment of experimental woodchip pad....................... 58

Appendix 2: Preliminary Study: Woodchip and Biochar Characterization-Control Study.. 62

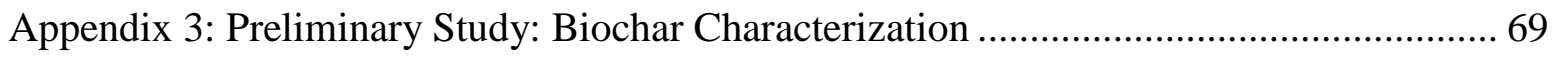

Appendix 4: Preliminary Study: Initial Bioreactor Trials..................................................... 71

Appendix 5: Preliminary Study: Limestone Characterization ............................................. 75

Appendix 6: Preliminary Study: Microbial Study ................................................................. 77

Appendix 7: Preliminary Study: Incubation times.................................................................. 81

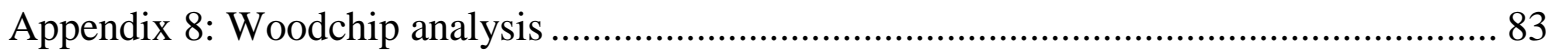




\section{List of Tables}

Page Number

Table 1. Denitrification half reactions, with associate enzymes (Bothe et. al, 2007)........45

Table 2. Nutrients in manure by species (Brown, 2013)............................46

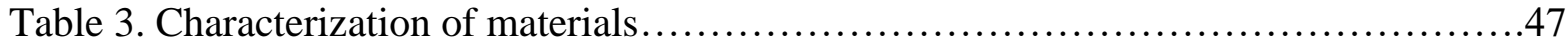

Table 4. Characterization of nutrient sources....................................... 48

Table 5. Main Effects summary table..............................................49

Table 6. Main effects by Treatment summary table..............................50

Table 7. Main effects by Hour summary table........................................51

Table A2-1 Characterization of liquid samples....................................64

Table A2-2. Characterization of solid samples...................................65

Table A3-1. Characterization of liquid samples.................................. 70

Table A4-1. Characterization of liquid samples...................................... 73

Table A5-1. Data for limestone characterization study............................. 76

Table A6-1. t-Test Paired Two Sample for Means................................... 80 


\section{List of Figures}

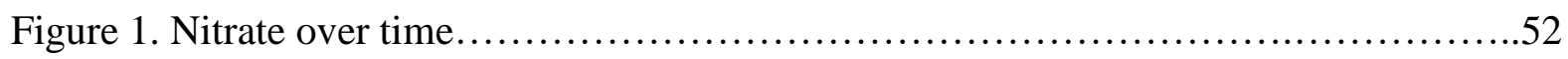

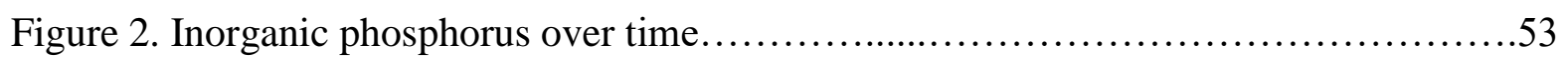

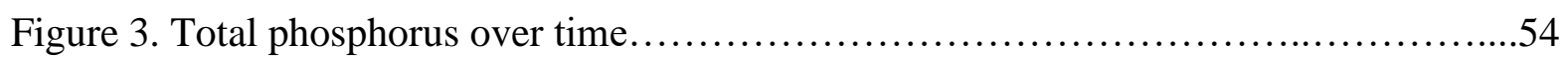

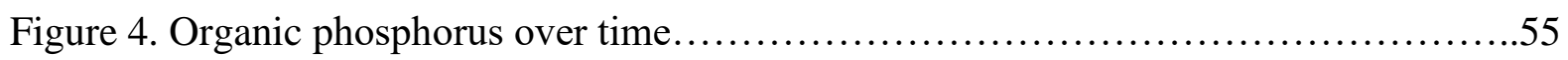

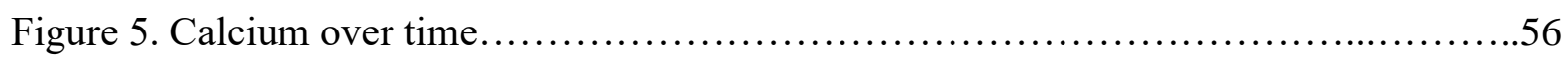

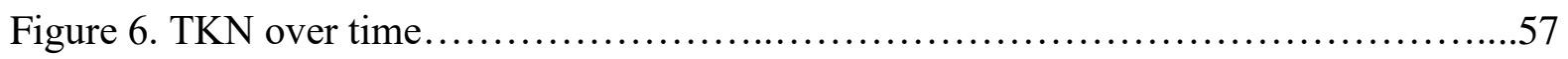

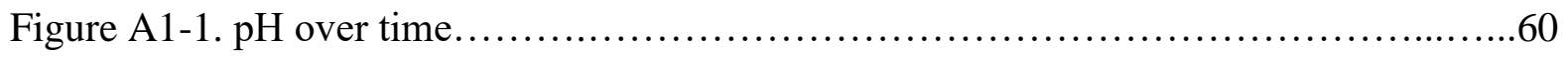

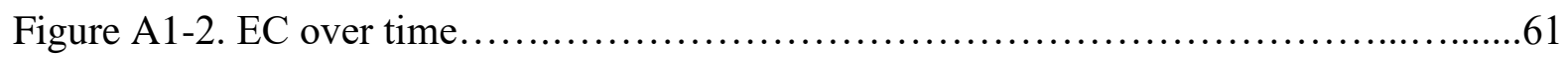

Figure A2-1 Inorganic phosphorus over time for the control experiment....................66

Figure A2-2. Nitrate over time for the control experiment..............................67

Figure A2-3. 600nm reading over time for the control experiment........................68

Figure A4-1. Nitrate levels for treatments over 24 hours................................ 74

Figure A6-1. Nitrate levels for treatments over 24 hours..............................79

Figure A7-1. Nitrate levels for treatments over 24 hours.............................. 82

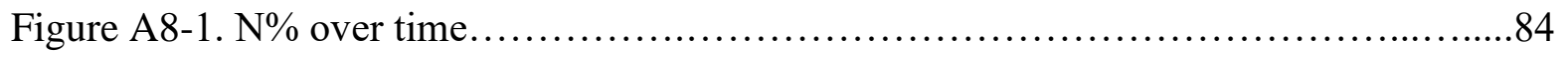

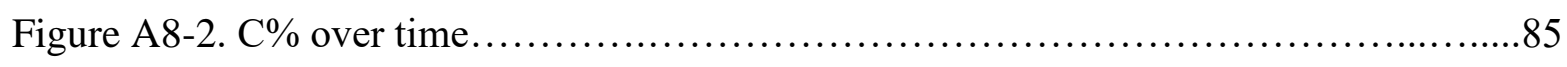

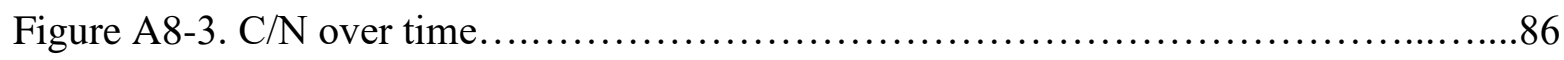




\section{Chapter 1}

\subsection{Thesis Overview}

Globally, water quality issues have been on the rise in recent years. As water resources have become scarce, it is ever the pressing issue to preserve what resources we have. The most prevalent of all water quality issues is the excessive amounts of nutrients, mainly nitrogen and phosphorus, reaching our water systems (US EPA, 2018). These nutrients have led to the degradation of aquatic systems and can also pose a risk to human and animal health. Primary sources for these nutrients are areas of urban and agricultural production, including fertilizers and manures (Lory et. al, 2006). Practices and other technologies have been put into place to help reduce the amount of nutrients accumulating within watersheds, while work has been done to reduce nutrients coming from manure sources, this issue is far from resolved. Manures and fertilizers are categorized as nonpoint source pollution, making them difficult to treat outright. One proposed method of reducing nutrient loads from manure sources can be the implementation of a denitrifying bioreactor

A denitrifying bioreactor is a newly adopted conservation practice developed for agricultural uses that consists of a microbial driven process for the treatment of tile drained agricultural runoff and is commonly used as an edge of field practice (Christianson et. al, 2012). Denitrifying bioreactors are intended to reduce nitrates to nitrogen gas, making them ideal for the treatment of agricultural fields but may also help treat part of the nutrient problem associate with manures (Christianson et. al, 2012). Using a novel redesign of this technology, in conjunction with other treatments or in areas with concentrated flow from manure sources such as stockpiles or confined feeding areas, reduction of these nutrients may be possible. However, nitrate is only part the issue with manures, as a large contribution of excessive phosphorus loads come from 
manure runoff and leach into our waterways. Biochar has been used to remove $\mathrm{P}$ from waste streams however, results are inconsistent, probably due to the inherent variability of different biochars (Bock et al., 2015, Ghezzehei et al., 2014, Christianson et al., 2011).

\subsection{Literature Review}

Excess nitrogen and phosphorus in surface waters are major concern. Monitoring over recent years has given us a clearer picture of the main contributors to the nutrient crisis, with agriculture indicated as a large source Agricultural production alone accounts for nearly 50\% of the nutrient sources reaching the Chesapeake Bay area, with an estimated 18-25\% coming solely from manure production (Chesapeake Bay Foundation, 2004). A common source of manure nutrients are concentrated animal feeding operations, or CAFOs. A CAFO is any animal feeding operation that has confined feedings for at least 45 days of the year, regardless of animal numbers. One of the largest sectors of these CAFOs in the U.S. is the beef cattle industry (USDA, 2017). Nutrients of concern resulting from the runoff and leaching from CAFOs are nitrogen and phosphorus. The most concerning form of nitrogen from manure is nitrate $\left(\mathrm{NO}_{3}{ }^{-}\right)$. Nitrate is soluble and can be leached quickly through the soil profile unless taken up by vegetation. Inorganic phosphorus in manure occurs as phosphate $\left(\mathrm{H}_{2} \mathrm{PO}_{4}{ }^{-}\right.$and $\left.\mathrm{HPO}_{4}{ }^{2-}\right)$. This inorganic form is available for plant uptake, but can also be readily lost via sediment transport. Other CAFO-related issues are increased numbers of disease producing bacteria, trace metals, and antibiotics. Nutrient-stimulated algal blooms also create economic costs for the people and businesses who use these waters as a means of income.

Algal blooms are stimulated by excessive amounts of nutrients and will continue to grow until they can no longer support themselves. Their death and subsequent decay depletes the water of oxygen resulting in hypoxia and the death of aquatic life. These blooms can also release toxins 
which can affect both the aquatic life and those who use the waters as a drinking source. Areas that have been affected by this hypoxia are known as dead zones, and are prevalent in both the Mississippi and Chesapeake watersheds (Goolsby et. al, 2001), and world-wide; the number of coastal dead zones has double every decade since the 1960s (Diaz, et. al, 2008). The dead zone in the Gulf of Mexico in 2017 was the largest on record (NOAA, 2017). Algal blooms and their associated issues have led to the development and enhancement of practices and standards we use to address these nutrient issues.

\subsection{Nitrogen and Phosphorus in the Environment}

Nitrogen and phosphorus are typically the most limiting nutrients in natural ecosystems. In agricultural cropping systems, they are applied in the largest amounts. All animal wastes contain $\mathrm{N}$ and $\mathrm{P}$; the concentrations depend on species and production system (Table 2). The more common types of livestock i.e. swine and cattle tend to have a higher manure nutrient content even when compared to other more uncommon livestock such as bison or elk when under a managed setting.

Form of nitrogen include, nitrogen gas, which is abundant in the atmosphere and organic and inorganic nitrogen, which can be found within soils. Nitrogen is of significant importance for all life, for proper growth and function. Due to this, nitrogen tends to be one of the most limiting nutrients in the natural environment (Kiba et. al, 2016). The nitrogen cycle is a naturally occurring biochemical process encompassing the various forms of nitrogen through atmospheric, terrestrial, and aquatic ecosystems (Killpack et. al, 1993). Many process are driven by living organisms such as bacteria to convert between the various forms (Kuypers et. al, 2018). Initially, nitrogen gas can be converted by nitrogen fixation to the ammonia or organic form which can be used for plant uptake (Johnson et. al, 2005) (Equation 1). 
dinitrogen gas $\left(\mathrm{N}_{2}\right) \rightarrow \operatorname{ammonia}\left(\mathrm{NH}_{3}\right) \rightarrow \operatorname{organic} \mathrm{N}\left(\mathrm{R}_{-} \mathrm{NH}_{2}\right)$

Biological fixation is common in legume species such as alfalfa that form symbiotic relationships with nitrogen fixing bacteria within their root nodules (Kuypers et. al, 2018). Fixation can also occur through lightening or through industrial fixation used to make fertilizers. Once fixed, several processes can occur. Mineralization can take place, through the microbial decomposition of organic nitrogen can be converted to ammonium (Johnson et. al, 2005) (Equation 2).

$\operatorname{organic} \mathrm{N}\left(\mathrm{R}-\mathrm{NH}_{2}\right) \rightarrow \operatorname{ammonia}\left(\mathrm{NH}_{3}\right) \rightarrow \operatorname{ammonium}\left(\mathrm{NH}_{4}{ }^{+}\right)$

Mineralization rates vary environmental factors such as $\mathrm{pH}$, temperature, and moisture as well as oxygen or aeration within soils (White, 2005). Typically soils with a low $(<30: 1) \mathrm{C} / \mathrm{N}$ ratio will go through this process. In cases where this ratio is larger, immobilization may occur, resulting in lower mineral forms of nitrogen in soils. Nitrification can occur next, which converts ammonium to nitrite and nitrate compounds through sequential oxidation by microbes (Johnson, et. al 2005) (Equation 3).

ammonium $\left(\mathrm{NH}_{4}^{+}\right) \rightarrow$ nitrite $\left(\mathrm{NO}_{2}^{-}\right) \rightarrow$ nitrate $\mathrm{NO}_{3}^{-}$

Nitrosomonas species are responsible for the conversion of ammonium to nitrite while Nitrobacter species convert nitrite to nitrate (Kuypers et. al, 2018). Some species of archaea bacteria and other species have the capabilities to perform both functions (Bothe, 2007). Nitrate is readily available to plants, but due to its mobility it is easily lost from systems, this is due to a net negative charge on both nitrate and soil resulting in loss of nitrate from leaching. Under the right conditions, denitrification can occur which is the conversion of nitrate through stepwise reductions back to nitrogen gas (Johnson et. al, 2005) (Equation 4). 
nitrate $\mathrm{NO}_{3}{ }^{-} \rightarrow$ nitrite $\left(\mathrm{NO}_{2}{ }^{-}\right) \rightarrow$ nitric oxide $(\mathrm{NO}) \rightarrow$ nitrous oxide $\left(\mathrm{N}_{2} \mathrm{O}\right) \rightarrow$ dinitrogen gas $\left(\mathrm{N}_{2}\right)$

This step can only occur under low oxygen conditions, as the presence of oxygen can deter denitrification. The bacteria species responsible for this step are numerous, and can function under a variety of conditions (Christianson et. al, 2011). Denitrification is common in soils that are poorly drained or have standing water such as wetland soils (Johnson et. al, 2005). Several other steps in the nitrogen cycle include, volatilization, which is the loss of nitrogen through the conversion of ammonia gas, and crop uptake which is the uptake of nitrate by plants (Kuypers et. al, 2018). Nitrogen is naturally occurring in all forms in the environment, going through various conversions depending on location. Of all the forms of nitrogen, nitrate is held at high importance for human needs such as in the agricultural sector but it also is of great importance in terms of environmental concerns.

Nitrate is readily present in both soils and waters in nature. Natural levels of nitrate vary depending on location, soil type, and surrounding land use, but are generally normal background levels for non-cropped lands range from 5-10 mg/L, 4-9 mg/L for groundwater, and some surface waters around 0-18mg/L (US Environmental Protection Agency, 1987). The push of urbanization as well as the increased use of chemical fertilizers and other nutrient based land applications over recent years has led to an increase in total nitrate levels in the environment. Groundwater contamination is a major concern for areas high in agricultural production that use such waters as a source for public drinking water. Similar issues with regards to surface water concentrations are also of concern. The main reason for this is the effect of aquatic health as well as human health, specifically in infants as the condition known as methemoglobinemia has been linked with the consumption of high 10mg/L nitrate drinking water (Darling et. al, 1942). This disease is not just limited to human health but also aquatic species. In fish species, this is known 
as nitrate toxicity or brown blood disease as normal hemoglobin is converted to methemoglobin which is a distinct brown color. This changes the color of the blood as well as the gills and will eventually lead to death. For this, the United States Environmental Protection Agency established a standard for drinking water at a limit of 10mg/L nitrate (US Environmental Protection Agency, 1995).

Phosphorus like nitrogen is a significant element for the proper function and growth of organisms. Natural sources of phosphorus in the environment come from the weathering of sedimentary rocks and minerals, which can take a long time before it is available for uptake (Filippelli et. al, 2002). Due to this phosphorus availability is highly limited. The phosphorus cycle, unlike the nitrogen occurs at a much slower rate. The main forms of phosphorus are; inorganic phosphorus (plant available), organic phosphorus, adsorbed phosphorus, and primary mineral phosphorus.

The initial step in the phosphorus cycle in the weathering of rocks, causing the release of inorganic phosphate. This can be found in both soils and water systems and is readily available for plant uptake. As plants die and decompose, organic phosphate is then added through the soil. Similar to nitrogen, this organic compound can be transformed back into the inorganic form of phosphorus through mineralization. Mineralization converts this organic form in plant available forms known as orthophosphates $\left(\mathrm{H}_{2} \mathrm{PO}_{4}{ }^{-}\right.$or $\left.\mathrm{HPO}_{4}{ }^{2-}\right)$ (Hyland et. al, 2005). Immobilization can also occur, causing the transformation of these available forms to unavailable organic forms. Phosphorus can also go through the process of adsorption and desorption. Adsorption is the chemical binding of inorganic phosphorus to the soil while desorption is the release of the bound phosphorus. Adsorption occur in soils that have a high iron or aluminum content due to the reactive of the compounds (Hyland et. al, 2005). Precipitation can occur if inorganic phosphorus 
is allowed to react with dissolved iron and aluminum in soil. However, there is a limit to the adsorption capability of soils. Excess amounts can result in net losses. Dissolved phosphorus can be lost from the system through runoff or groundwater, or through particulate phosphorus by erosion or the movement of water on soil particles (Conley et. al, 2009).

Issues with phosphorus loss in regards to human and environmental health and quality mainly focus on eutrophication. However, due to the finite availability of rock phosphate the concept of peak phosphorus has arisen (Tiessen, 2011). This concept deals with the production and supply of phosphorus. Since it is one of the most limiting nutrients in soils and agricultural production phosphorus is added via fertilization. Rock phosphate is use in the production of this, but the issue of the depletion of our reserves has risen. While the dominant theory on when we will run out of this material varies, with some saying 50-100 years while others predict several hundreds of years, the fact remains that this is an issue that needs to be addressed (Cordell et. al, 2009). Most phosphorus is lost from our systems due to the over applications and runoff. Limiting our use of phosphorus based applications may help with reductions, but there may also be some possibilities of potentially capturing and reusing phosphorus that typically would be lost by the capture of dissolved or particulate phosphorus.

The main issue with the leaching or runoff of nitrogen and phosphorus nutrients within waters is the occurrence of eutrophication (Smith, 1999). Since both nutrients are usually limiting, when excessive amounts are present in waterways aquatic plants and algae flourish and grow. As this vegetation is left unchecked and unlimited they have the potential to block out sunlight for any lower vegetation causing them to die and decay. As decomposition of this plant material occurs, oxygen is depleted from the water. This term is designated as hypoxia or the depletion of oxygen. This can result in the asphyxiation of aquatic species as dissolved oxygen 
levels drops. Areas sensitive to this occurrence are those that receive waters from agricultural uses. Global, areas affected by this have increase, as well as an increase in the total number of these sites (NOAA, 2017).

A secondary, often overlooked issue with nutrient pollution are both the direct and indirect economic impacts. For many, direct losses from nutrient pollution is prevalent, spanning individuals to communities whose livelihood depends on good water quality. Such sectors include, commercial fisheries, tourism, and drinking water treatment. An estimated average impact of $\$ 18$ million occurs yearly in the United States from the effects of harmful algal blooms (Anderson et. al, 2000). Similar issues occur globally. Developing areas such as China, India, Africa are dealing with the spread and threat of algal blooms, as they become more prevalent and diverse (Anderson, 2014). This threatens the global supply, as these areas are some of the largest producers of food fish and other aquaculture. As dead zones and algal blooms increase, these markets are pushed further and further out to avoid areas of high nutrient pollution, however the associated costs as well as overcrowding or inaccessibility of such areas may drive prices up or put producers out of business.

While fisheries may feel the direct impact of poor water quality, the tourism sector often gets hit with indirect economic damage from algal blooms and nutrient pollution. Business such as restaurants, lodging, recreation, boating, and other water related industries and those close by may experience losses during harmful algal blooms (HAB). In Florida between years 1995-1999 reported up to a $29 \%$ decline in restaurant revenues and $35 \%$ in lodging revenue during the occurrence of HABs (Larkin et. al, 2007). When compared to other environmental events, HABs caused significant losses in revenue than any other event. Similar to the tourism industry, the real estate sector has similar losses for properties near water bodies affected by nutrient pollution and 
occurrence of algal blooms. For homes near lakes that have experienced algal blooms in 6 Ohio counties, losses of $11-17 \%$ were shown, with properties adjacent experiencing a loss of $22 \%$ (Wolf et. al, 2017).

Other additional losses occur such as the increased cost of drinking water treatment. With the increase in nutrients specifically nitrates within drinking water, or the occurrence of algal blooms in municipal drinking water additional treatments may need to be done. This can greatly increase the cost of water treatment, as well as result in additional byproducts in the water from treatment (Davenport et. al, 2011). Indirect losses can also occur on production lands. Since nutrients are removed from operations, those nutrients are not used for production resulting in an economic loss. This can occur as either direct fertilizer costs, or indirectly as time and labor. Overall, while nutrient pollution has detrimental effects on the environment, it is important to also realize the economic impacts it has.

\subsection{Denitrifying Bacteria}

Microbial denitrification is mainly carried out by a group of bacteria referred to as denitrifying bacteria. This encompasses a wide range of bacterium, such as those from the Pseudomonas and Bacillus groups. These facultative aerobic bacteria have the ability to switch from aerobic respiration to denitrification when oxygen is limited, therefore switching their terminal electron acceptor (TEA) to nitrate to produce energy. The most common denitrification process involves the complete denitrification of nitrate back to nitrogen gas (Bothe, 2007) (Equation 5):

$$
2 \mathrm{NO}_{3}{ }^{-}+10 \mathrm{e}^{-}+12 \mathrm{H}^{+} \rightarrow \mathrm{N}_{2}+6 \mathrm{H}_{2} \mathrm{O}
$$

Denitrification is step-wise reduction of nitrate using several enzymes such as nitrate reductase, and nitrite reductase to transform nitrate to dinitrogen gas (Table 1-1, Paul, 2007). 
Complete denitrification however does not always occur. By-products of nitric oxide and nitrous oxide, both of which are detrimental to the ozone, can occur (Eldor, 2015).

\subsection{Denitrifying Bioreactors}

Current practices have been developed and used to help alleviate nutrient runoff, from buffer strips to conservation tillage however most of these practices are limited in their removal of nutrients from manure sources in terms of effectiveness and design (Christensen, et. al, 2011). Denitrifying bioreactors are a relatively new technology that has been used to treat and reduce nutrient loads from drained agricultural fields, but may also have some effect on nutrients from manure. A typical setup consists of an excavated pit, with size depending on the projected nutrient concentrations from current tile drainage (USDA, 2017). These pits are then lined to prevent leaching into nearby groundwater and contamination by surroundings soils, then filled (Addy et. al, 2016). Typically, they are filled with a carbon substrate such as woodchips, depending on available resources, costs, and location. The pit is then covered with a layer of soil for both protection and to help keep conditions within the bioreactors oxygen free. Open top bioreactors have also been used, with similar results. Differences between the two types include protection from external factors such as surface water and burrowing animals for covered reactors, whereas open top reactors tend to be less compacted which can improve hydraulic conductivity and are easier to replenish the carbon substrate if needed (Addy et. al, 2016). For these reactors, influent is allowed to enter and flow at a designed rate via a flow control device (Christensen et. al, 2012). This retention time is based on the size and nutrient source of the drainage. Excess nutrients are then treated before leaving the system. Current systems are being used as edge of field practices with direct discharge into surface waters. To reduce the nutrient influx, these sub-surface systems work by allowing the carbon substrates to be used as a fuel 
source for anaerobic denitrifying bacteria. These bacteria, in turn, convert the excess nitrates into unreactive nitrogen gas via microbial denitrification.

\subsection{Factors Influencing Denitrification}

The rate at which denitrification occurs depends on temperature, $\mathrm{pH}$, carbon source, construction design, and time. Temperature has a wide range of effects on the denitrification process. Since microbial denitrification is a biological process, it tends to increase with temperature. Lower removals rates at temperature less than $6{ }^{\circ} \mathrm{C}$ have been observed when compared to intermediate temperatures of $6-16.9^{\circ} \mathrm{C}$ with most data reporting higher removals for intermediate to high temperatures $<16.9^{\circ} \mathrm{C}$ (Addy et. al, 2016). There is some evidence of improved removals at lower temperatures, based on carbon source and nutrient load, but in general warmer temperatures have a much greater removal rate (Warneke et. al, 2011).

While temperature plays a role in the rate and effectiveness of denitrification, $\mathrm{pH}$ effects have been observed. For $\mathrm{pH}$, based on experiments using activated sludge, the optimal range observed for the denitrifiers was 6.5-8.5 which is consistent with other observed ranges (Painter et. al, 1983, Watson et. al, 1989). The average $\mathrm{pH}$ for bioreactors tend to be between $6.9-8.0$ and increase over time, which provides ideal conditions in terms of $\mathrm{pH}$ for the denitrification process (Warneke et. al, 2011). Since the introduction of manure will take place in these reactors it is important to note the characteristic manure $\mathrm{pH}$. Initially cattle manure tends to be more neutral to alkaline, with an average $\mathrm{pH}$ range of 7.0 - 8.0. When added to soils, it increases soil $\mathrm{pH}$ (Whalen et. al, 2000). This range is within the limits of microbial denitrification needed for the proper operation of a bioreactor. However, there is no data on the change in $\mathrm{pH}$ in reactors with manure additions or on $\mathrm{pH}$ changes with time. Based on the change in $\mathrm{pH}$ of soils, with 
manure additions it is possible an increase $\mathrm{pH}$ shift will be observed when manure is added to bioreactors.

Another factor that can influence nutrient removal in these systems is the type of carbon source used. A variety of carbon substrates have been tested for use in reactors including hard and soft woods, and green wastes such as wheat refuse and corn cobs. Of these media, wood sources specifically those in chip form, are the most commonly used media due to availability and low cost. Not all wood sources are equal however. Due to their structural and chemical difference, softwoods tend to be less dense and degrade faster depleting their available carbon at a higher rate which in turn limits microbial functions and removal rates (Cameron et. al, 2010). Generally, a mix of local woods is sufficient for the use in the reactor and tend to have a longexpected lifespan when compared to other sources. Special care should be made with high tannin species such as oak which can inhibit microbial growth.

Feedstock source influences on nutrient reductions are not consistent. Promising shortterm results have been observed with corn cobs and wheat refuse with removal rates of up to 6 times faster when compared to wood feed stock. However, while they have been shown to reduce more initial nitrate than wood sources and other green wastes, this may only be a temporary reduction with the differences among sources becoming more similar with time. A major issue with the use of these green waste materials is the amount of leaching at both start up and throughout the life of the bioreactor. These materials do have some adverse effects, such as high initial dissolved organic carbon loading. The tradeoff however is that they require fewer materials and have a lower cost while still maintaining higher removal rates if only for the short term (Cameron et. al, 2010). Since this is still a new technology, work is still being done to assess long term removal rates from different feed stocks however, there is consensus that more 
stable sources such as hardwood chips or a mix of different feed stocks are the best option to achieve optimal nutrient removal.

\subsection{Woodchip Chemistry}

An associated issue with the use of woodchips are their potential to readily leach compounds into the environment which can be detrimental to water quality. This type of leachate is generally low in nutrients while high in chemical oxygen demand decreasing with age due to natural processes, therefore while initial startup effects of a bioreactor may be seen, such negative discharge spikes are only temporary (Kannepalli et. al, 2016). An important compound that may be of significance is the production and release of tannins. Tannins are polyphenic compounds produced by plant species, namely as secondary metabolites used for predation defense. These compounds have a distinct brown color when leached into surface waters and are usually acidic in nature. Typically, for tree species, hardwoods such as oak or cedar tend to have much higher tannin levels than softwoods such as pine (Addy, et. al, 2016). For this reason, it is recommended not to use woodchip species solely from hardwoods as these compounds have been shown to have adverse effects on microbial populations. There are several theories as to how these compounds inhibit microbial activity. The main purposed mechanism is the inhibition of extracellular microbial enzymes, as well as a deprivation of substrates required for microbial growth or direct an action on the microbial metabolism through the inhibition of oxidative phosphorylation (Scalbert, 1991). While this does have implications for the proper function of denitrifiers in these systems, it also may be a pathway for the inhibition or reduction of pathogenic bacteria such as Escherichia coli (E. coli) as this could potentially be treated within a bioreactor. 


\subsection{Decomposition of wood}

Wood decomposition is a complex process, due to the resistance of lignin to decomposition. Due to this, specialized wood decaying fungi are needed for the decomposition to occur. Examples of such fungi involved in this process are Serpula lacrymans and Phanerochaete chrysosporium which inflict brown rot and white rot (Srivastava et. al, 2013). Both employ enzymatic activates to break down the components of the wood, brown rot breaking down the hemicellulose and cellulose in the wood while white rot breaks down the lignin (Witomski et. al, 2014). Some species of bacteria and fungi live in together, while the fungi decay the wood, the bacteria use the products leftover for their own metabolism and functions (Johnston et. al, 2016). Such bacteria could be those that are capable of denitrification. The rate however for wood decomposition depends on not only wood type and makeup but depends on the type of fungi and bacteria present.

\subsection{E. coli Background}

Another type of bacteria that can be present in low oxygen conditions is Escherichia coli (E. coli) This facultative aerobe that can switch to fermentation under such conditions. Most strains of this bacterium are found in the intestinal tract of warm blooded animals and are typically used as an indicator species for fecal contamination. Several foodborne illnesses are linked to this bacterium making it a pathogen of concern when dealing with surface waters and water quality. Animal manures are a major source of this bacterium, due to either improper management or storage of wastes. A study looking at the reductions of fecal coliforms, using E. coli as an indicator, reported significant reductions $\left(2.9 \log _{10}\right)$ with the use of a woodchip denitrifying bioreactor (Rambags et. al, 2016). In this study however, the source of the bacterium 
was wastewater collected from human sourced waste. This does have implication on the impact these reactors may have on the reduced of these pathogens within animal waste treatment.

\subsection{Denitrifying Bioreactor Designs}

Design of the reactor may also influence removal rates. There are several different types of bioreactors: denitrification walls which work by intercepting and treating shallow ground water, denitrifying beds which captures and treats discharge from concentrated areas such as tile drains, and denitrifying layers which use horizontal layers of carbon material to treat water before reaching ground water systems. In terms of removal of nutrients, denitrifying beds show the greatest removal rates, when compared to the other designs and is the more common practice used. One of the major components of the operation of these bioreactors is the retention time or residence time of the nutrient-laden water within the bioreactor. Lower retention times characteristically equate to lower nutrient removal and are typically anything less than 6 hours. Conflicting data for the most optimal retention times has been observed with some data showing between the $6-20$ hours range and others around 24 hours as the most effective time to balance nutrient removal and removal efficiency (Addy et. al, 2016, Lepine, 2016). Efficiencies are the measured percentage of nitrates converted directly to nitrogen gas, with other subsequent forms taken from measured nitrate concentrations (Healy et. al, 2012). There are few studies that have looked at bioreactors over longer periods of time. Based on current studies, it is suggested that removal rates decline with time (Addy et. al, 2016).

\subsection{Manure Characteristics}

While these systems have been traditionally used to treat tile drainage, animal manure treatment may be a secondary use for these systems. Manure is the combination of animal feces and urine that may also contain bedding materials and feed waste. Manure composition and 
nutrient content varies based on the production system and animal types present. Feed, bedding, and other inputs also contribute to the distribution of nutrients within manure. Major nutrients present in manures are nitrogen, phosphorus, and potassium. These nutrients come from excess feeds these animals are receiving. Typically, $50-90 \%$ of all nutrients taken in by livestock is excreted out into waste (Manitoba, 2015). Other nutrients include sulfur and other micronutrients and trace elements. Some recorded values include: $0.35 \mathrm{~N}, 0.18 \mathrm{P}_{2} \mathrm{O}_{5}$, and $0.29 \mathrm{~K}_{2} \mathrm{O}$ lbs. per day per $1000 \mathrm{lbs}$. animal daily, while other estimate values of $0.31 \mathrm{~N}, 0.19 \mathrm{P}_{2} \mathrm{O}_{5}$, and $0.26 \mathrm{~K}_{2} \mathrm{O}$ lbs. per day per 1000 lbs. of animal daily (Lorimor et. al, 2004, Randall et. al, 2006).

\subsection{Relevance}

Beef cattle production in the United States accounts for one of the largest sources of

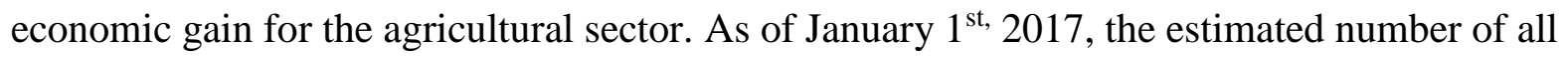
cattle in the United States alone was 93.6 million head (USDA, 2017). Manure production from these sites vary, with a rough average of $92 \mathrm{lbs}$. produced daily per confined head of cattle (Lorimor, 2004). The confinement period usually extends through the cooler, wetter portions of the year stretching from December to March. While confinement can result in a buildup of manures, the alternative is to allow the animals pasture. This can lead to a variety of problems such as increased soil erosion and compaction which leads to nutrient runoff.

The beef cattle industry in West Virginia consisted of roughly 405,000 head of cattle for the 2016-2017 production period (USDA, 2017). Due to a high seasonal precipitation average of approximately $112 \mathrm{~cm}$, pasture vulnerability due to wetness is typical (US Climate Data, 2017). This causes cattle confinement to extend from late November early December into early or late March in order to prevent field damage. During this time manure is collected and stored for future applications. However, both manure storage and animal confinement lead to nutrient 
runoff. In order to prevent these nutrients from accumulating in local watersheds and contributing to aquatic degradation they must be treated before entering any surface or ground waters. Due to its location, operations in West Virginia can have impacts on both the Mississippi and Chesapeake Bay watersheds, however more nutrient loss occurs in the eastern part of the state.

While manure serves as a major source of nitrogen, which can be remediated through these reactors, phosphorus also needs to be addressed. Some data suggests the addition of biochar can help remediate the phosphorus coming from these systems making it an ideal addition to denitrifying bioreactors. Biochar is the product of pyrolysis of biomass, with the intended purpose of use as a soil amendment, which differentiates it from charcoal and charcoallike products. Biochar has been shown to improve soil fertility by reducing nitrogen leaching, increasing soil $\mathrm{pH}$, increasing nutrient retention, and reducing $\mathrm{N}_{2} \mathrm{O}$ emissions as well as other functions (Anderson et. al, 2011, Lehmann et. al, 2001). Types or feed stock of biochar ranges from wood products such as wood chips and sawdust to production wastes and animal byproducts each with a varying final nutrient content. Carbon, nitrogen, phosphorus, potassium content as well as $\mathrm{C} / \mathrm{N}$ ratios have been recorded over a variety of feed stocks with an average of, C: 543, N: 22.3, P: 23.7, K: $24.3 \mathrm{~g} / \mathrm{kg}^{-1}$ and C/N: 67 (Lehmann et. al, 2009). As for pH, biochar tends to be more alkaline in nature with an average $\mathrm{pH}$ range of $7.0-8.0$. There is evidence of nutrient reductions and microbial influences with the additions of these biochars in bioreactors and in soils. Statistically significant nutrient reductions have been observed with biochar, with up to $97 \%$ nitrate reduction and $65 \% \mathrm{P}$ reduction over time for bioreactors (Bock et. al, 2015). However, this data is not consistent within studies, with some reporting no net reduction for total phosphorus with biochar additions in these reactors (Bock et. al, 2018). The inconsistency may 
lie in the vast differences between biochar and their characteristics, such as feedstock and size. However, there is evidence as its use as a soil amendment with positive effects on, fecal coliform reductions, reductions of $\mathrm{N}_{2} \mathrm{O}$ gas, and improved soil microbial health (Anderson et. al, 2011). Coliform reductions may have been due to the adsorption of the microbes into the macro and micro pores of the biochar (Arief et. al, 2016). These pores can also provide habitation for other microorganisms due to their high surface area and ability to adsorb organic matter which makes them suitable for colonization which in turn can help promote the denitrification process (Lehmann et. al, 2009). Related to manure nutrients, sorption of ammonium and phosphate has been shown to occur with biochar, with the possible mechanisms co-adsorption with calcium and surface exchange respectively (Sarkhot et. al, 2013). While some of the evidence specifically for bioreactors remains larger unknown or inconsistent, its use in soils may supports its possible use in a bioreactor system specifically designed to treat manure runoff.

Currently these reactors are used to mainly treat excess nitrogen from waters, with some work done on phosphorus removal but there are other nutrients and compounds that should be considered for removal in these systems. Based on materials and nutrient loads, suggested discharge of total organic carbon, methane, ammonium, nitrous oxide, greenhouse gases, carbon dioxide, and various other compounds can be observed within these reactors. However, discharge depends greatly on nutrient source and feed stock, as one study done with a mixture of woodchips and sawdust showed no significant production of any adverse compounds from the system, while others observed high amounts of total organic carbon and nitrous oxide releases respectively from green wastes (Warneke et. al, 2011). 


\subsection{Research Objective}

The overall goal of this study was to determine if a denitrifying bioreactor could be used to treat or reduce manure-sourced nutrients. In order to determine reductions in of manure nutrients, a novel redesign of the current practice was done. This involved the inclusion of a biochar treatment as well as adding a limestone base. The specific research objectives were:

Objective 1) Determine the reduction in nitrogen and or phosphorus nutrients in a novel redesign denitrifying bioreactor in a lab setting.

Objective 2) Quantify the effects of biochar addition on phosphorus removal

\subsection{Research Hypothesis}

Based on similar studies with the inclusion of biochar, it is hypothesized that with biochar additions, phosphorus reductions would be observed (Bock et. al, 2015). 


\section{Chapter 2: Materials and Methods}

Type as well as nutrient content of materials must be characterized before experimentation in order to understand and account for nutrient content and other observations taken during testing. For this study, characterization was performed on the initial carbon media, in this case woodchips and biochar, and the nutrient and incubation source used.

\subsection{Organic Carbon-Based Media}

Woodchips were a mixture of local wood species including white oak, poplar, and pine and were obtained from Green Team Pellets (Carmichaels, PA). Chips were sieved to a size range of $9.5-38.9 \mathrm{~mm}$ in total width. Fines were removed during the sieving process. The biochar was a commercially available product produced by Cool Terra (Cool Planet, Camarillo, CA) from coconut shells. This material boasts about improving soils through water retention and providing an environment within the biochar for microbial growth. They also claim it can help address environmental issues in animal production by "helping to reduce volatiles and odor while still capturing valuable nutrients like nitrogen" (Cool Planet). Data on $\mathrm{pH}$, electrical conductivy, total carbon, nitrogen, sulfur, and $\mathrm{C} / \mathrm{N}$ ratios were determined for both materials to assess initial nutrient values, as described below (Table 3).

\subsection{Nutrient Sources}

Runoff was collected at drainage point on the WVU Animal Sciences Research Farm experimental over-wintering woodchip pad (Christianson et. al, 2017). This served as a natural source of bacteria needed for the proper function of the bioreactors. The chip pad is currently used as a loafing area for dairy cattle, however this use is inconsistent. Use of the pad is mainly during milking operations, however several weaned calves and dry heifers remain on site within in the milking parlor. Generally cattle are granted free access to the chip pad while in the parlor. 
Their residency is not set, as they are moved within the farm weekly to daily during normal farm operations. During the events when cattle are present on the pad, they are limited to the smaller sections as the rest are fenced off. Vegetation has also been allowed to grow on site, reducing effects from any manure deposits by these cattle as well as any surface runoff. Runoff collection occurred within 24 hours of a rain event, from two sampling pipes located at the end of the chip pad. Manure used in the experiment was also collected from the WVU Animal Sciences Research Farm with collection occurring in pasture from a small ( $<20$ head) Hereford herd residing on the farm. Manure that was collected from the cattle used in the length of the experiment were from the same herd under the same management. The manure was used to create a manure tea to serve as the effluent source and to simulate manure runoff. Typically, manure tea is used as fertilizer for home gardens and is similar to compost tea. Determination of $\mathrm{pH}$, electrical conductivity, nitrate, inorganic phosphorus, and total Kjeldahl nitrogen for both sources were collected, as described below (Table 4).

\subsection{Treatment Vessels}

Treatment vessels selected for the study consist of $3.8 \mathrm{~L}$ glass containers. Containers were Mainstays brand 1-gallon beverage dispenser (Walmart Inc.). Containers consisted of a glass body, with an iron lid, plastic spigot and O-rings to prevent leaking. To reduce loss of solids, the internal port of the spigot was covered with cheesecloth. Plastic film was used over the top opening of the jars before capping to minimize the interchange of oxygen into the jar. Aluminum foil was used to cover jars to prevent interference from sunlight. Between studies, jars were scrubbed then rinsed with hot water and air dried. The internal parts of all spigots were scrubbed and rinsed to prevent buildup and issues during draining. 


\subsection{Methods}

The organic carbon media $\mathrm{pH}$ and electrical conductivity (EC) were determined using a Mettler Toledo SevenCompact pH meter and SevenCompact conductivity meter (Mettler Toledo International, Inc. Schwarzenbach, Switzerland) at 1:1 liquid to solid ratio in distilled, deionized water (DDIW). Samples shaken for 1 hour before analysis. Total carbon, nitrogen, and sulfur concentrations of the solid samples was determined by dry combustion (Vario MAX cube (Elementar, Langenselbold, Germany). Carbon-to-nitrogen ratio $(\mathrm{C} / \mathrm{N})$ was calculated.

Liquid samples were passed through Fisher Scientific Q2 Quantitative Filters (Thermo Fisher Scientific, Waltham, Massachusetts) before analysis. Sample pH and EC were determined (Mettler Toledo International, Inc. Schwarzenbach, Switzerland). Nitrate-nitrogen was determined colorimetrically following the APHA Standard Method $4500-\mathrm{NO}_{3}{ }^{-}$B Ultraviolet Spectrophotometric Screening Method using a Varian Cary 50 UV-VIS Spectrophotometer equipped with a fiber-optic probe). Inorganic phosphorus was determined colorimetrically using the ammonium molybdate-antimony potassium tartrate-ascorbic acid method (Murphy, 1962). Dissolved iron, phosphorus, and calcium were determined by ICP-OES (Perkin-Elmer Optima DV2100, Perkin-Elmer Corp. Norwalk, CT). Total Kjeldahl nitrogen was determined using method SM 4500- $\mathrm{NH}_{3} \mathrm{C}$ at the WVDA Moorefield Testing Laboratory.

The nutrient source for the bioreactors was a manure tea. Approximately $16 \mathrm{~L}$ of water was placed into a 5-gallon bucket. Manure (800g) was weighed, wrapped in cheesecloth then placed in the water. Cheesecloth was used to reduce the amount of solids in the tea to minimize clogging in the reactor. This mixture was allowed to sit at room temperature for 72 hours, with occasional stirring to reduce settling. 


\section{Chapter 3: Batch Study}

\subsection{Introduction}

For this study, a batch study was conducted to determine nutrient reductions using a denitrifying bioreactor from a manure source. Initially several smaller studies were used to look at design specs as well as material data. This included data on discharge concentrations from the materials with and without a nutrient source, incubation times and sources, and initial trials.

Sampling of the runoff from the WVU Animals Sciences Research Farm overwintering woodchip pad was performed February $1^{\text {st }}-25^{\text {th }} 2017$ (Appendix 1). Runoff was collected from an end of pipe collection area, as close to rain events as possible. Electrical conductivity and $\mathrm{pH}$ data were collected for all samples during this time. The main purpose of this study was to determine trends and values of discharge $\mathrm{pH}$ for the site as this collected runoff was to be used in experiments. The $\mathrm{pH}$ levels during this period stayed well within the generally preferred range of denitrifiers, 6.5-8.5 (Painter et. al, 1983, Watson et. al, 1989). Based on this information, runoff from this site could potentially be suitable for use in the batch study.

Data for both the woodchips and woodchip biochar mixtures were collected using distilled, deionized water (DDIW) to characterize leachate from the materials over a 24 hour period (Appendix 2). Liquid samples were filtered and analyzed for $\mathrm{pH}, \mathrm{EC}, \mathrm{NO}_{3}^{-}, \mathrm{PO}_{4}{ }^{-3}$, and colorimetrically at $600 \mathrm{~nm}$, while solid samples of the media were analyzed for total carbon, nitrogen, sulfur, and $\mathrm{C} / \mathrm{N}$ ratio. Overall the addition of biochar only had an effect on the $\mathrm{pH}$ of the solution and the inorganic phosphorus levels being discharged. For samples with the biochar, $\mathrm{pH}$ was typically higher than samples with only woodchips. This is consistent with the literature, as biochars tend to be more alkaline in character (Lehmann, 2009). For inorganic phosphorus, when compared to woodchips only, the woodchip biochar samples had a much higher 
concentration. This evidence may support that this biochar may serve as a source rather than a sink for phosphorus. However, since this was run under controlled conditions, this may not be the outcome in future studies. There in some disagreement in the literature, as some support reductions with biochars, and others do not (Bock et. al, 2015, Bock et. al, 2018). This may be due to differences in feedstock and other factors. Application rate may also be an issue as well, as rates are not constant or well defined. The nitrate for the experiment went down over time, however there was an initial increase in concentration. Chip size, and type may have been a factor in this, as well as the absorptive property of the wood itself.

Based on the data collected, and additional study looking at biochar rates was performed using a sterile phosphorus solution (Appendix 3). This study focused on just biochar, with no woodchip additions to evaluate leaching of nutrients from the biochar. An application rate of $20 \%$ and $50 \%$ was chosen based on rates used in other studies, which typically apply from 10$20 \%$, with the $50 \%$ application done to look at effects at increased rates (Easton, 2015). Similar to the previous study, biochar was shown again to increase total phosphorus levels even in the presence of solution phosphorus. While $\mathrm{pH}$ benefits may be observed with increased concentrations, phosphorus levels also increased.

Initial test trials on the functionality and performance of the bench top bioreactors with a primary purpose of determining if nitrate reductions could be observed were performed (Appendix 4). For the initial trial, due to timing and weather, a manure slurry was made instead of using chip pad runoff or manure tea. A treatment control of woodchips and $1 \%, 2,5 \%, 5 \%$, and $10 \%$ biochar were done in duplicate. Sampling was taken after a 72 hour incubation period over 24 hours. These samples were analyzed for $\mathrm{pH}, \mathrm{EC}, \mathrm{NO}_{3}{ }^{-}$, and $\mathrm{TKN}$. For this study, several issues arose. The first issue was that the average $\mathrm{pH}$ was lower than what is preferred by 
denitrifying bacteria. This may have been due to the leaching of organic acids from the woodchips. Nitrate levels in the reactor were also problematic. During the first hour for most treatments a decrease in nitrate concentration was observed. This trend however did not continue as all treatments saw an increase in nitrate concentration ending with values higher than the initial observation. Since the focus was on nitrate, phosphorus data was not collected. Based on this data, the addition of limestone to control $\mathrm{pH}$ was implemented. Another issue was the possibility of too few denitrifying colonies within the reactor, possibly stemming from insufficient incubation source or time.

A design trial run was done to account for the addition of limestone to control $\mathrm{pH}$ within the reactor (Appendix 5). Data on $\mathrm{pH}, \mathrm{EC}$, and $\mathrm{NO}_{3}{ }^{-}$where collected over 48 hours of testing at 4 different rates: $100 \mathrm{~g}$ limestone, $200 \mathrm{~g}$ limestone, $100 \mathrm{~g}$ limestone $+200 \mathrm{~g}$ woodchips, and $200 \mathrm{~g}$ limestone $+200 \mathrm{~g}$ woodchips. The $\mathrm{pH}$ values for all treatments were well within the range need for denitrifiers, with only slight differences between. The limestone itself was not a source of nitrate while the treatments with woodchips contributed some, but this was consistent with the material data. Since the manure sourced used tended to be slightly lower in $\mathrm{pH}$ than needed, the 200g limestone treatment was selected to be used for further studies.

The next redesign run focused indirectly on the microbial populations (Appendix 6). Runoff from the WVU Animal Sciences Research Farm overwintering chip pad was used as a means to inoculate the jars with natural bacteria. Incubation times were also tested, at 72 hours, 24 hours, and 1 hour. Treatments consisted of 200g of woodchips with $200 \mathrm{~g}$ of limestone. Collected runoff was allowed to sit in the jars during the designated incubation periods. They were then drained and refilled with the additional runoff. Samples were collected over 48 hours, filtered then analyzed for $\mathrm{NO}_{3}{ }^{-}$. Reductions were observed in 72 hour incubation and the 24 hour 
incubation treatments with no reductions in the 1 hour incubation treatment. There was no significant difference between the 72 hour incubation and the 24 hour incubation (alpha 0.05), however this supports a 72 hour incubation time as reported by other studies as a sufficient time for microbial inoculation and for the use of the runoff as a source (Bock et. al, 2015). For this reason, a 72 hour hold was designed to be used to ensure proper incubation time and colonization of denitrifying bacteria.

One last study was performed, testing all the all new design as well as additional work on incubation times using new nutrient sources (Appendix 7). Runoff from the chip pad was used for incubation, however jars were refilled with a manure tea mixture after being drained. Treatments were as follows: Treatment 1: 72 hour hold, Treatment 2: 24 hour hold, Treatment 3: 24 hours hold using refrigerated runoff, Treatment 4: 72 hour hold without limestone added. This was to infer if the changes made would have an impact on the function of the bioreactors. No significant differences were observed between treatments; all experienced decreased nitrate concentrations. Based on the procedure for the manure tea and ease of experimentation, the 72 hour hold was selected to be used for the batch study.

These preliminary studies were used to design the batch study. Changes were made to provide the best possible lab conditions for the colonization of denitrifiers within the bioreactors. This included controlling $\mathrm{pH}$ and obtaining natural sources of bacteria. From this point, the batch study was performed taking into account all of these changes.

\subsection{Experimental Design}

Treatment vessels selected for the study consist of 3.8L glass containers. Nine containers were used with samples collected from a premade spigot near the bottom of the jar. Cheesecloth was wrapped around the drainage area to prevent solids from leaving the jar. Containers were 
filled with a mixed species woodchips (200g) for all treatments as well as a base of limestone chips and powder (200g) this was used to keep the $\mathrm{pH}$ in an optimal range for denitrifiers as the manure source was slightly below optimal as well as reduce the effect of organic acid releases observed by the woodchips. Six of the jars received a biochar additions as either as a low treatment, $10 \%$ biochar $(20 \mathrm{~g})$ or as a high treatment, $50 \%$ bichar $(100 \mathrm{~g})$ by weight. Lids were sealed with plastic wrap to minimize oxygen interference and jars were also wrapped in aluminum foil to reduce light exposure. Treatments were replicated three times. To begin the trial, runoff collected from the WVU Animal Sciences Research Farm experimental overwintering chip pad added to all jars (2L) and allowed to incubate for 72 hours. This ensured the establishment of microbial populations within the media. (Bock et. al, 2015). This incubation time was also shown to be sufficient in a preliminary run performed on incubation times.

After this incubation period, the jars were drained then refilled with $2 \mathrm{~L}$ of the prepared manure tea. Once the tea had been added to the jars, $150 \mathrm{~mL}$ of liquid was collected at hour 0 (time when tea was added), then at 2, 4, 8, 12, 16, and 24 hours. This time was selected based on retention times for installed bioreactors. After collection, samples were stored at $0{ }^{\circ} \mathrm{C}$ and then filtered through a Fisher Scientific Q2 Quantitative Filter before analysis. A sample of the woodchip solids were collected at hour 0 and 24 then allowed to air dry at room temperature. These samples were also refrigerated until analysis. Due to the small size and difficulty of collection, the biochar was not evaluated post study. Samples from both tea mixtures, as well as the farm effluent were also collected for analysis. Liquid samples were analyzed for, nitrate, total Kjeldahl nitrogen, inorganic phosphorus, total phosphorus, calcium, iron, $\mathrm{pH}$, and electrical conductivity. Solid samples were analyzed for total carbon, nitrogen, sulfur and $\mathrm{C} / \mathrm{N}$ ratio. 


\subsection{Statistical Methods}

Normally distributed variables were analyzed by repeated measures ANOVA using spatial power covariance structure (calcium, inorganic phosphorus, total phosphorus, and nitrate; irregularly spaced in time) and autoregressive covariance structure (total Kjeldahl nitrogen, woodchip C\% and woodchip C/N; regularly spaced in time). Orthogonal contrast for main effect of treatment in ANOVA was tested to see if the control group differed from the biochar treatment groups (Treatment 1, 10\% and Treatment 2, 50\%) and if biochar treatment $1(10 \%)$ differed from biochar treatment $2(50 \%)$. Variables that were not normally distributed (pH, iron and woodchip N\%), where first transformed, however that did not correct the distribution, therefore a nonparametric procedure (Kruskal-Wallis) was used, followed by nonparametric multiple comparison method comparing each biochar treatment to the control (Steel).

Data were analyzed using JMP and SAS software (JMP®, Version Pro 12.2, SAS Institute Inc., Cary, NC, Copyright @2015; SAS®, Version 9.3, SAS Institute Inc., Cary, NC, Copyright (C2002-2010). Significance criterion alpha for all tests was 0.05.

\section{Chapter 4: Results and Discussion}

\subsection{Batch Study}

Nitrate levels overall showed an increase in concentration from their initial values. There was an initial drop in concentration for the $50 \%$ biochar treatment between hour 0 and hour 4 (Figure 1). The 10\% biochar treatment followed a similar trend to that of the control group. Overall, the $50 \%$ biochar treatment had a lower final nitrate concentration than the control and the $10 \%$ biochar treatment groups, and its final concentration was similar to its initial value (difference of $0.1 \mathrm{mg} / \mathrm{L}$ ). For both time and treatments there was a significant difference as well 
as a difference between the control and biochar treatments, and between the biochar treatments. (Table 5). For inorganic phosphorus, there was a significant difference between treatments, and time, and between the control and treatments and between the treatments (Table 5). Concentrations fluctuated over time, however, remained relatively around the same concentration during the duration of the experiment, with only a slight increase in final concentrations $(0.5-1.0 \mathrm{mg} / \mathrm{L} \mathrm{P})$ (Figure 2). Total phosphorus was significant between treatments, time, and the interaction of the two as well as between the control and treatments and between treatments (Table 5). Total phosphorus also remained around the same concentration throughout the experiment (Figure 3). Organic phosphorus, overall, decreased with time (Figure 4). The inorganic form was the most prevalent in the system. Calcium concentrations were significant over time, as well as for treatments and the interaction of time and treatment (Table 5). There was also a significant difference between the control and the biochar treatments as well as a difference between the $10 \%$ biochar treatment and the $50 \%$ biochar treatment (Table 5). For the control and the $10 \%$ biochar treatment, calcium overall increased and had higher concentration than the $50 \%$ biochar treatment which remained around the same concentration (Figure 5). TKN was significant for time and the interaction of treatment and time, however there was no difference between the control and treatments or among the treatments (Table 5). Overall, an increase in TKN from the initial and final concentration was observed (Figure 6).

\subsection{Woodchips}

(Refer to Appendix 8).

\subsection{Discussion}

Overall, nitrate levels did not decrease or follow trends as reported by other studies, either in the lab or the field (Bock et. al, 2015, Hoover et. al, 2016). The reason for this may be 
due to the nature of the experiment, or the material used in the experiment. Gaps in the literature concerning the growth and colonization for in-lab studies of denitrifying bacteria in these reactors in unclear. Many studies either dose chips with a nutrient solution for a set time, or simply began sampling without an incubation period (Easton, et. al, 2015, Sharrer, 2016). The 72 hour incubation period used for this study was based on what data was available for lab studies. Some preliminary data showed a decrease in level in nitrate over time (Appendix 2, 6, and 7), however, this trend was not always followed in all experiments, even with similar incubation methods. The use of the overwintering chip pad runoff was the preferred method of incubation, to inoculate the lab jars with the naturally occurring bacteria, however, no work was completed on characterizing the bacteria present. Based on the limited studies have been reported, the main factors that influence denitrifying bacteria are $\mathrm{pH}$, available nitrate, temperature, and available carbon. Warneke et. al, (2011) reported that greater denitrification occurred when increased available carbon and higher temperatures were achieved. For their study, they heated their systems to roughly $27^{\circ} \mathrm{C}$. For the length of the batch study performed here, the experimental vessels were kept at room temperature $\left(20-25^{\circ} \mathrm{C}\right)$, indicating that temperature may not have been a cause of the lack of denitrification. and suggesting there may have been an inadequate supply of microbially available carbon to support bacterial colonization. Woodchip size could have played a role in this.

Woodchip size is directly related to its surface area. It has been reported that larger sized chips $(9.5 \mathrm{~mm}-13 \mathrm{~mm})$ have a reduced ability to reduce nutrient leaching by decreasing the amount of available carbon as well as the reduced space for the formation of biofilms (Peterson et. al, 2015). A study using an in-field reactor, with a similar feedstock choice, reported issues with denitrification due to carbon content. Hartz et. al (2017) determined that carbon enrichment 
could improve denitrification due to availability of carbon for microbial use. Using soluble carbon in the form of methanol they reported almost complete nitrate reductions, compared to their control of a woodchip only bioreactor which had only minimal reductions over the length of their study. This may be due to a lack of available carbon from woodchip species and may explain the observance of poor nitrate reductions in this study. Decomposition of the wood needed to provide an adequate amount of carbon for bacteria may not have had enough time to occur. The process of establishing or colonizing the needed fungi may occur in established bioreactors, however, would be severely restricted in this lab study meaning carbon availability may have played a huge role in the lack of bacteria activity. In regards to the lower concentration of nitrate for the batch study in the 50\% biochar treatment, this may be due to the amount of available carbon produced by the biochar, since the $10 \%$ biochar treatment had a much lower application rate which may be why this effect was not observed in that treatment (Hassanpour et. al, 2017). Overall, the nitrate concentration was under the set discharge limit of 10mg/L (3.99 $\mathrm{mg} / \mathrm{L} \mathrm{NO}_{3-}, 4.05 \mathrm{mg} / \mathrm{L} \mathrm{NO}_{3^{-}}$, and $1.76 \mathrm{mg} / \mathrm{L} \mathrm{NO}_{3^{-}}$averaged over time for the control, the $10 \%$ biochar treatment, and the $50 \%$ biochar treatment respectively).

Phosphorus concentrations over the length of the study remained nearly constant, with an average concentration over time of $10.50 \mathrm{mg} / \mathrm{L} \mathrm{P}, 10.70 \mathrm{mg} / \mathrm{L} \mathrm{P}$, and $12.00 \mathrm{mg} / \mathrm{L}$ respectively for the inorganic phosphorus portion. Inorganic phosphorus accounted for roughly 93\% (average over all treatments and times) of the total phosphorus concentration. The concentration of the inorganic phosphorus was significantly higher in the 50\% biochar treatment than the control or the $10 \%$ biochar treatment. This may be to the nature of the biochar. In an earlier study (Appendix 3) this biochar was shown to be source of phosphorus rather than a sink as previously hypothesized. This is consistent with other works, Bock et al, (2018) and Christianson et. al, 
(2011) that biochar applications may not decrease phosphorus levels within bioreactors. Biochar applications as soil amendments have been shown to reduce phosphorus concentrations, through the co adsorption of calcium in alkaline soils (Lehmann et. al, 2009). While the calcium concentrations were lower in the both biochar treatments when compared to the control, there is no evidence to this as mechanism to remove phosphorus. The organic portion only accounted for minimal portion, with minimal fluctuations over time and treatments $(1.05 \mathrm{mg} / \mathrm{L} \mathrm{P}, 1.01 \mathrm{mg} / \mathrm{L} \mathrm{P}$, and $0.95 \mathrm{mg} / \mathrm{L} \mathrm{P}$ organic phosphorus concentrations averaged over time and treatment). While the biochar did not reduce the amount of phosphorus, and may have been a source, the woodchips themselves may also have been a source. As reported by Peterson, et. al, (2015) total phosphorus was shown to increase with woodchip size. This may be due to leaching as the wood begins to decay, and depending on species, there may be a large concentration within the wood. However, this effect would likely not be seen in the time frame of the experiment unless additional prior decomposition occurred (Romero et. al, 2005).

For the analysis of TKN, this correlates to other work done, attributed to start up effects (Lopez, et. al, 2017; Cameron et. al, 2010). A possible reason for this is that areas within the reactor that may still be aerobic, inhibiting denitrification and instead promoting nitrification. There has be limited work on the exact time required for the startup of a reactor, meaning, for this experiment there may not have been enough time for establishment of microbial populations in order to get nutrient reductions (Lynn, 2015). This may also have had an influence on the performance of the reactors. If communities were not well established, it is possible that leaching from the woodchips was the main source of nitrate within the system. It is also possible that other studies may be incorrectly identifying denitrification as a removal mechanism and not removal from woodchip adsorption, as identified in Appendix 2. 


\section{Chapter 5: Summary and Conclusions}

Overall, the expected outcomes of the experiment did not support the hypothesis. Phosphorus levels did not show reductions with the addition of biochars but instead showed an increase, possibly due to feedstock. Nitrate concentrations also did not meet expectations, with an overall increase. There was an effect by the biochar on nitrate concentration but a further study would be needed to determine the reason. Recommendations for future work would be to establish an on-site reactor to promote denitrification, paying special attention to media and nutrient source as well as startup times. Once established, microbial communities have been shown to remain stable over time however, effectively establishing them may be no easy task (Bock et. al, 2015). This may prove to be of importance in the future, as these systems become more readily available and understood. While this experiment did not demonstrate effective nitrate removal from manure-sourced nutrients, there is enough evidence to warrant further studies, including a field experiment. 


\section{Literature Cited}

Addy, K., Gold, A. J., Christianson, L. E., David, M. B., Schipper, L. A., and Ratigan, N. A. (2016). Denitrifying bioreactors for nitrate removal: a meta-analysis. Journal of Environmental Quality, 45(3), 873-881.

Anderson, C. R., Condron, L. M., Clough, T. J., Fiers, M., Stewart, A., Hill, R. A., Sherlock, R. R. (2011). Biochar induced soil microbial community change: implications for biogeochemical cycling of carbon, nitrogen and phosphorus. Pedobiologia, 54(5/6), 309320.

Anderson, D. (2014). HABs in a changing world: a perspective on harmful algal blooms, their impacts, and research and management in a dynamic era of climactic and environmental change. Harmful Algae 2012 : Proceedings of the 15th International Conference on Harmful Algae : October 29 - November 2, 2012, CECO, Changwon, Gyeongnam, Korea / Editors, Hak Gyoon Kim, Beatriz Reguera, Gustaaf M. Hallegraeff, Chang Kyu Lee, M., 2012, 3-17.

Anderson, D., Kaoru, Y., White, A., Woods Hole Oceanographic Institution, United States. National Oceanic and Atmospheric Administration, and Marine Policy Center (Woods Hole Oceanographic Institution). (2000). Estimated Annual Economic Impacts from Harmful Algal Blooms (HABs) in the United States (Whoi, 2000-11). Woods Hole, Mass.: Woods Hole Oceanographic Institution. doi:10.1575/1912/96.

Bock, E. M., Coleman, B. S. L., and Easton, Z. M. (2018). Performance of an under-loaded denitrifying bioreactor with biochar amendment. Journal of Environmental Management, $217,447-455$. 
Bock, E. M., Coleman, B., and Easton, Z. M. (2016). Effect of biochar on nitrate removal in a pilot-scale denitrifying bioreactor. Journal of Environmental Quality, 45(3), 762-771.

Bock, E., Smith, N., Rogers, M., Coleman, B., Reiter, M., Benham, B., Easton, Z. (2015). Enhanced nitrate and phosphate removal in a denitrifying bioreactor with biochar. Journal of Environmental Quality, 44(2), 605-613.

Bothe, H., Ferguson, S., and Newton, W. (2007). Biology of the nitrogen cycle. Amsterdam: Elsevier.

Brown, C. (2013). Available nutrients and value for manure from various livestock types. Factsheet Order No. 13-043, AGDEX 538 Ontario Ministry of Agriculture, Food and Rural Affairs (OMAFRA). Retrieved October 12, 2018 from http://fieldcropnews.com/wp-content/uploads/2015/03/Nutrient-Value-of-Manure.pdf.

Cameron, S. G., and Schipper, L. A. (2010). Nitrate removal and hydraulic performance of organic carbon for use in denitrification beds. Ecological Engineering, 36(11), 15881595.

Chesapeake Bay Foundation. (2004). Manure's Impact on Rivers, Streams and the Chesapeake Bay. Retrieved October 4, 2018 from http://cdm16064.contentdm.oclc.org/cdm/ref/collection/p266901coll7/id/1420.

Christianson, L., DeVallance, D., Faulkner, J., and Basden, T. (2017). Scientifically advanced woody media for improved water quality from livestock woodchip heavy-use areas. Frontiers of Environmental Science and Engineering, 11(3), 2. 
Christianson, L., Helmers, M., Bhandari, A. (2012). A Practice-oriented Review of Woodchip Bioreactors for Subsurface Agricultural Drainage. Applied Engineering in Agriculture. 28. 861-874. 10.13031/2013.42479.

Christianson, L., Hedley, M., Camps, M., Free, H., Sagger, S. (2011) Influence of Biochar Amendments on Denitrification Bioreactor Performance. Report Massey University. Retrieved October 4, 2018 from http://www.massey.ac.nz/ flrc/workshops/11/Manuscripts/Christianson_2011.pdf.

Christianson, L., Helmers, M., Bhandari, A., Castello, A., and Christianson, R. (2010). Technical Note: Hydraulic Property Determination of Denitrifying Bioreactor Fill Media. Applied Engineering in Agriculture, 26(5), 849-854.

Conley, D. J., Paerl, H. W., Howarth, R. W., Boesch, D. F., Seitzinger, S. P., Havens, K. E., Lancelot, C., Likens, G., E., (2009). Controlling Eutrophication: Nitrogen and Phosphorus. Science. 323: 1014-1015.

Cordell, D., Drangert, J., White, S. (2009). The story of phosphorus: Global food security and food for thought. Global Environmental Change. 19 (2): 292-305. doi:10.1016/j.gloenvcha.2008.10.009.

Darling, C. R., Roughton, W. J., F. (1942). The effect of methaemoglobin on the equilibrium between oxygen and hemoglobin. America Journal of Physiology-Legacy Content., 137, pp. 56-68.

Davenport, T., Drake, W. (2011). EPA Commentary: Grand Lake St. Marys, Ohio - The Case for Source Water Protection: Nutrients and Algae Blooms. Lakeline, Fall 2011: 41-46. 
Diaz, R. J., Rosenberg, R. (2008). Spreading Dead Zones and Consequences for Marine Ecosystems. Science. 321 (5891): 926-9. doi:10.1126/science.1156401. PMID 18703733.

Elementar. (2000). Operating instructions Vario MAX CNS; Elementar Analysensysteme. GmbH: Hanau, Germany.

Eldor, A. (2015). Soil microbiology, ecology, and biochemistry (4th ed.). Chapter 14 Amsterdam: Elsevier.

Easton, Z. M., Rogers, M., Davis, M., Wade, J., Eick, M., and Bock, E. (2015). Mitigation of sulfate reduction and nitrous oxide emission in denitrifying environments with amorphous iron oxide and biochar. Ecological Engineering, 82, 605-613.

Filippelli G., M. (2002). The Global Phosphorus Cycle. Reviews in Mineralogy and geochemistry 48: $391-425$.

Ghezzehei, T. A, Sarkhot, D. V., Berhe, A. A. (2014). Biochar can be used to capture essential nutrients from dairy wastewater and improve soil physico-chemical properties. Solid Earth. 5. 953-962. 10.5194/se-5-953-2014.

Goolsby, D. A., Battaglin, W.A., Aulenbach, B.T., Hooper, R.P. (2001). Nitrogen input to the Gulf of Mexico. Jornal of Environmental Quality. 30: 329-336.

Hartz T, Smith R, Cahn M, Bottoms T, Bustamante S, Tourte L, Johnson K, Coletti L. (2017). Wood chip denitrification bioreactors can reduce nitrate in tile drainage. Calif Agr 71(1):41-47. https://doi.org/10.3733/ca.2017a0007. 
Hassanpour, B., Giri, S., Pluer, W. T., Steenhuis, T. S., and Geohring, L. D. (2017). Seasonal performance of denitrifying bioreactors in the Northeastern United States: Field trials. Journal of Environmental Management, 202, 242-253.

Healy, M. G., Ibrahim, T. G., Lanigan, G. J., Serrenho, A. J., and Fenton, O. (2012). Nitrate removal rate, efficiency and pollution swapping potential of different organic carbon media in laboratory denitrification bioreactors. Ecological Engineering, 40, 198-209.

Hoover, N. L., Bhandari, A., Soupir, M. L., and Moorman, T. B. (2016). Woodchip denitrification bioreactors: impact of temperature and hydraulic retention time on nitrate removal. Journal of Environmental Quality, 45(3), 803-812.

Hyland, C., Ketterings, Q., Dewing, D., Stockin, K., Czymmek, K., Albrecht, G., Geohring, L. (2005). Phosphorus Basics - The Phosphorus Cycle. Cornell University Cooperative Externison. Retreived October 142018 from http://nmsp.cals.cornell.edu/publications/factsheets/factsheet12.pdf.

Ismail, S. A., Prasher, S. O., Chénier, M. R., and Patel, R. M. (2016). Evaluation of biochar soil amendments in reducing soil and water pollution from total and fecal coliforms in poultry manure. Canadian Biosystems Engineering, 58, 1.21-21.31.

Johnson, C., Albrecht, G., Ketterings, Q., Beckman, J., Stockin, K. (2005). Nitrogen Basics The Nitrogen Cycle. Cornell University Cooperative Extension. Retrieved Ocotber 14, 2018 from http://cceonondaga.org/resources/nitrogen-basics-the-nitrogen-cycle.

Johnston, S. R., Boddy, L., and Weightman, A. J. (2016). Bacteria in decomposing wood and their interactions with wood-decay fungi. FEMS Microbiology Ecology, 92(11). https://doi-org.www.libproxy.wvu.edu/10.1093/femsec/fiw179 
Kannepalli, S., Strom, P. F., Krogmann, U., and Miskewitz, R. (2016). Characterization of wood mulch and leachate/runoff from three wood recycling facilities. Environmental Management, 182, 421-428.

Kiba, T., Krapp, A. (2016). Plant Nitrogen Acquisition Under Low Availability: Regulation of Uptake and Root Architecture. Plant and Cell Physiology, 57(4), 707-714.

Killpack, S., Daryl, B. (1993). Nitrogen in the Environment: Nitrogen Cycle. University of Missouri Cooperative Extension Service. Retrieved October 14, 2018 from https://extension2.missouri.edu/WQ252.

Kuypers, M. M. M., Marchant, H. K., and Kartal, B. (2018). The microbial nitrogen-cycling network. Nature Reviews Microbiology, 16, 263.

Larkin, S. L., and Adams, C. M. (2007). Harmful Algal Blooms and Coastal Business: Economic Consequences in Florida. Society and Natural Resources, 20, 849-859.

Lehmann, J., and Joseph, S. (2009). Biochar for Environmental Management: Science and Technology: London: Earthscan. Print.

Lehmann, J., Rillig, M. C., Thies, J., Masiello, C. A., Hockaday, W. C., and Crowley, D. (2011). Biochar effects on soil biota - a review. Soil Biology and Biochemistry, 43(9), 18121836.

Lepine, C., Christianson, L., Sharrer, K., and Summerfelt, S. (2016). Optimizing hydraulic retention times in denitrifying woodchip bioreactors treating recirculating aquaculture system wastewater. Journal of Environmental Quality, 45(3), 813-821. 
Lopez-Ponnada, E. V., Lynn, T. J., Peterson, M., Ergas, S. J., and Mihelcic, J. R. (2017). Application of denitrifying wood chip bioreactors for management of residential nonpoint sources of nitrogen. Journal of Biological Engineering, 11(1), 16.

Lorimor, J. (2004). Manure characteristics (Vol. Rev., 2nd ed): Ames, Iowa: Iowa State University, 2004. Retrieved October 4, 2018 from http://msue.anr.msu.edu/uploads/files/ManureCharacteristicsMWPS-18_1.pdf.

Lory, J., and Cromley, S. (2006). Nutrients and Water Quality for Lakes and Streams. G9221. University of Missouri Cooperative Extension Service. Retrieved October 4, 2018 from http://extension.missouri.edu/publications/DisplayPub.aspx?P=G9221.

Lynn T. J, Yeh D. H, Ergas S. J. (2015). Performance and longevity of denitrifying wood-chip biofilters for stormwater treatment: a microcosm study. Environmental Engineering Science. 2015;32:321-30.

Manitoba. (2015). Properties of Manure. https://www.gov.mb.ca/agriculture/environment/nutrient-management/pubs/propertiesof-manure.pdf .

Milling, A., Kehr, R. D., Wulf, A., and Smalla, K. (2005). Survival of bacteria on wood and plastic particles: Dependence on wood species and environmental conditions. Holzforschung, 59(1), 72-81.

Murphy J. and Riley J. P., (1962). A modified single solution method for determination of phosphate in natural waters. Analytica Chimica Acta, 27: 31-36. 
NOAA. (2017). Gulf of Mexico 'dead zone' is the largest ever measured. Retrieved October 4, 2018 from http://www.noaa.gov/media-release/gulf-of-mexico-dead-zone-is-largest-evermeasured.

Peterson, I. J., Igielski, S., Davis, A. P. (2015). Enhanced denitrification in bioretention using woodchips as an organic carbon source. Journal of Sustainable Water in the Built Environment, 1 (4).

Painter, H. A., and Loveless, J. E. (1983). Effect of temperature and $\mathrm{pH}$ value on the growth-rate constants of nitrifying bacteria in the activated-sludge process. Water Research, 17(3), 237-248.

Paul, E. (2007). Soil microbiology, ecology, and biochemistry (3rd ed.). Amsterdam: Academic Press.

Rambags, F., Tanner, C. C., Stott, R., and Schipper, L. A. (2016). Fecal bacteria, bacteriophage, and nutrient reductions in a full-scale denitrifying woodchip bioreactor. Journal of Environmental Quality, 45(3), 847-854.

Randall, J., Maurice, L. E., and Larry, C. B., Kevin H. E., Stephen S. F., James J. H., Martin J. J., Harold M. K., Karen M., Michael J. M., and Jon N. R. (2006). Ohio Livestock Manure Management Guide (Bulletin 604, pp. 118): Ohio State University Extension.

Romero, L. M, Smith T. J III, Fourqurean J. W. (2005). Changes in mass and nutrient content of wood during decomposition in a south Florida mangrove forest. J. Ecol. 93:618-31

Sharrer, K. L., Christianson, L. E., Lepine, C., and Summerfelt, S. T. (2016). Modeling and mitigation of denitrification 'woodchip' bioreactor phosphorus releases during treatment of aquaculture wastewater. Ecological Engineering, 93, 135-143. 
Sarkhot, D. V., Ghezzehei, T. A., and Berhe, A. A. (2013). Effectiveness of biochar for sorption of ammonium and phosphate from dairy effluent. Journal of Environmental Quality, 42(5), 1545-155.

Scalbert, A. (1991). Antimicrobial properties of tannins. Phytochemistry, 30(12), 3875-3883.

Smith, V. H., Tilman, G. D., and Nekola, J. C. (1999). Eutrophication: impacts of excess nutrient inputs on freshwater, marine, and terrestrial ecosystems. Environmental Pollution, 100(1), 179-196.

Srivastava, D. S., Kumar, R., and Singh, V. (2013). Wood Decaying Fungi. LAP LAMBERT Academic Publishing, Germany.

Tiessen, H. (2011). Phosphorus Availability in the Environment. eLS. doi:10.1002/9780470015902.a0003188.pub2.

US Climate Data. (2017). Temperature - Precipitation - Sunshine - Snowfall. Retrieved October 4, 2018 from http://www.usclimatedata.com/climate/west-virginia/united-states/3218

USDA. (2017). Cattle. Retrieved October 4, 2018 from http://usda.mannlib.cornell.edu/MannUsda/viewDocumentInfo.do?documentID=1017.

USDA, WV NRCS. (2017). Conservation Practice Standard 605 - Denitrifying Bioreactor.

US Environmental Protection Agency. (1987). Estimated national occurrence and exposure to nitrate and nitrite in public drinking water supplies. Washington, DC, United States Environmental Protection Agency, Office of Drinking Water.

US Environmental Protection Agency. (1995). Drinking Water Regulations and Health Advisories, Office of Water, Washington, D.C. 
US Environmental Protection Agency. (2018). Nutrient Pollution. Retrieved October 4, 2018 from https://www.epa.gov/nutrientpollution.

Whalen, J. K., Chang, C., Clayton, G. W., and Carefoot, J. P. (2000). Cattle manure amendments can increase the $\mathrm{pH}$ of acid soils. Soil Science Society of America Journal, 64(3), 962966.

Watson, S. W., Bock, E., Harms, H., Koops, H-P., Hooper, A. B. (1989). Nitrifying bacteria. In: Staley J T, Bryant M P, Pfennig N, Holt J G, editors. Bergey’s Manual of Systematic Bacteriology. Vol. 3. Baltimore, Md: The Williams and Wilkins Co. pp. 1808-1834.

Warneke, S., Schipper, L. A., Bruesewitz, D. A., McDonald, I., and Cameron, S. (2011). Rates, controls and potential adverse effects of nitrate removal in a denitrification bed. Ecological Engineering, 37(3), 511-522.

Warneke, S., Schipper, L. A., Matiasek, M. G., Scow, K. M., Cameron, S., Bruesewitz, D. A. (2011). Nitrate removal, communities of denitrifiers and adverse effects in different carbon substrates for use in denitrification beds. Water Research (Oxford), 45(17), 54635475.

White, R. E. (2005). Principles and Practice of Soil Science: The Soil as a Natural Resource (4th ed.). Blackwell Publishing. ISBN 0-632-06455-2. 384 pages.

Witomski, P., Olek, W., and Bonarski, J. T. (2014). Effects of White and Brown Rot Decay on Changes of Wood Ultrastructure. BioResources, 9(4), 7363-7371. Retrieved from http://www.libproxy.wvu.edu/login?url=http://search.ebscohost.com/login.aspx?direct=tr ue $\& \mathrm{db}=\mathrm{a} 9 \mathrm{~h} \& \mathrm{AN}=117103099$ 
Wolf, D., and Klaiber, H. A. (2017). Bloom and bust: Toxic algae's impact on nearby property values. Ecological Economics, 135, 209-221. 
Tables and Figures

Table 1. Denitrification half reactions, with associate enzymes (Bothe et. al, 2007)

\begin{tabular}{lll}
\hline Equation & Enzyme & End-Product \\
\hline $\mathrm{NO} 3-+2 \mathrm{H}++2 \mathrm{e}-\rightarrow \mathrm{NO} 2-+\mathrm{H} 2 \mathrm{O}$ & nitrate reductase (Nar) & nitrite \\
$2 \mathrm{NO} 2-+4 \mathrm{H}++2 \mathrm{e}-\rightarrow 2 \mathrm{NO}+2 \mathrm{H} 2 \mathrm{O}$ & nitrite reductase (Nir) & nitric oxide \\
$2 \mathrm{NO}+2 \mathrm{H}++2 \mathrm{e}-\rightarrow \mathrm{N} 2 \mathrm{O}+\mathrm{H} 2 \mathrm{O}$ & Nitric oxide reductase (Nor) & nitrous oxide \\
$\mathrm{N} 2 \mathrm{O}+2 \mathrm{H}++2 \mathrm{e}-\rightarrow \mathrm{N} 2+\mathrm{H} 2 \mathrm{O}$ & Nitrous oxide reductase (Nos) & dinitrogen gas \\
\hline
\end{tabular}


Table 2. Nutrients in manure by species (Brown, 2013)

\begin{tabular}{llll}
\hline & Total N & P2O5 & K2O \\
\hline Type of manure & $\%$ & lb/ton & 12.3 \\
Hog $^{\mathrm{a}}$ & 0.93 & 9.0 & 13.2 \\
Dairy & & \\
Beef & & \\
Bison & 0.72 & 3.7 & 14.3 \\
Elk & 0.92 & 6.1 & 0.8 \\
Red Deer & 0.40 & 0.6 & 2.6 \\
\hline denotes average over DM content & 0.73 & 1.8 & 4.3
\end{tabular}


Table 3. Characterization of substrate materials in bioreactors

\begin{tabular}{llllllc}
\hline Sample & $\mathrm{pH}$ & $\mathrm{EC}(\mu \mathrm{S} / \mathrm{cm})$ & $\mathrm{N} \%$ & $\mathrm{C} \%$ & $\mathrm{~S} \%$ & $\mathrm{C} / \mathrm{N}$ ratio \\
\hline Woodchips $^{1}$ & 4.69 & 106.7 & 0.10 & 45.84 & 0.04 & 441.40 \\
Biochar $^{1}$ & 6.91 & 2.92 & 0.53 & 55.85 & 0.04 & 103.31 \\
\hline
\end{tabular}

${ }^{l}$ Values denote an average value over several trials 
Table 4. Characterization of collected and prepared nutrient sources used in bioreactors

\begin{tabular}{lcclcc}
\hline Sample & $\mathrm{pH}$ & $\mathrm{EC}(\mu \mathrm{S} / \mathrm{cm})$ & $\mathrm{NO}_{3}{ }^{-} \mathrm{mg} / \mathrm{L}$ & Inorganic P mg/L P & $\mathrm{TKN}$ \\
\hline Chip Pad Runoff $^{1}$ & 7.55 & 871 & 6.05 & 9.02 & 12.46 \\
Manure Tea $^{1}$ & 6.8 & 259 & 2.43 & 14.6 & 33.71 \\
\hline
\end{tabular}


Table 5. Main Effects summary table

\begin{tabular}{|c|c|c|c|c|c|}
\hline \multicolumn{4}{|c|}{ Effect Test } & \multicolumn{2}{|c|}{ Orthogonal contrast: LSM (p-value) } \\
\hline Test & Trt & $\mathrm{Hr}$ & Trt $\times \mathrm{Hr}$ & Control vs Biochar Trts & Biochar Trt 1 vs Trt 2 \\
\hline \multirow[t]{2}{*}{ IP } & $0.003 *$ & $0.003 *$ & 0.704 & $10.50 \pm 0.22 \mathrm{vs}$ & $10.79 \pm 0.22 \mathrm{vs}$ \\
\hline & & & & $11.52 \pm 0.15(0.009)^{*}$ & $12.25 \pm 0.22(0.003)^{*}$ \\
\hline \multirow[t]{2}{*}{$\mathrm{TP}$} & $0.005^{*}$ & $0.001 *$ & $0.001 *$ & $11.55 \pm 0.19 \mathrm{vs}$ & $11.81 \pm 0.19$ vs \\
\hline & & & & $12.38 \pm 0.14(0.013)^{*}$ & $12.95 \pm 0.19(0.006)^{*}$ \\
\hline \multirow[t]{2}{*}{$\mathrm{NO}_{3}-$} & $0.002 *$ & $<0.0001^{*}$ & 0.120 & $4.30 \pm 0.32$ vs $2.91 \pm 0.22$ & $4.05 \pm 0.32$ vs $1.76 \pm 0.32$ \\
\hline & & & & $(0.012) *$ & $(0.002) *$ \\
\hline \multirow[t]{2}{*}{ TKN } & 0.588 & $0.002 *$ & $0.007 *$ & $28.04 \pm 3.64 \mathrm{vs}$ & $27.56 \pm 4.64 \mathrm{vs}$ \\
\hline & & & & $30.07 \pm 2.57(0.664)$ & $32.59 \pm 3.64(0.366)$ \\
\hline \multirow[t]{2}{*}{$\mathrm{Ca}$} & $0.007 *$ & $<0.0001^{*}$ & $<0.0001 *$ & $41.34 \pm 3.02 \mathrm{vs}$ & $32.17 \pm 3.02 \mathrm{vs}$ \\
\hline & & & & $25.92 \pm 2.14(0.006)^{*}$ & $19.67 \pm 3.02(0.026)^{*}$ \\
\hline \multirow[t]{2}{*}{$\mathrm{C} \%$} & 0.638 & $0.001 *$ & 0.468 & $39.53 \pm 1.32 \mathrm{vs}$ & $38.27 \pm 1.32 \mathrm{vs}$ \\
\hline & & & & $39.173 \pm 0.94(0.834)$ & $40.07 \pm 1.32(0.374)$ \\
\hline \multirow[t]{2}{*}{$\mathrm{C} / \mathrm{N}$} & 0.538 & 0.667 & 0.816 & $72.81 \pm 1.36 \mathrm{vs}$ & $73.05 \pm 1.36 \mathrm{vs}$ \\
\hline & & & & $73.97 \pm 0.963(0.515)$ & $74.88 \pm 1.36(0.379)$ \\
\hline
\end{tabular}

*Denotes significance (Alpha $=0.05)$ 
Table 6. Main effects by Treatment summary table

\begin{tabular}{|c|c|c|c|}
\hline \multicolumn{2}{|c|}{1 Way Test } & \multicolumn{2}{|c|}{ Nonparametric Comparisons With Control Using Steel Method (p-Value) } \\
\hline Test & $\mathrm{p}$ value & Control vs Biochar Trt 1 & Control vs Biochar Trt 2 \\
\hline $\mathrm{N} \%$ & 0.833 & - & - \\
\hline
\end{tabular}


Table 7. Main effects by Hour summary table

\section{Way Test}

\begin{tabular}{|c|c|c|c|c|c|c|c|}
\hline Test & & & & & & & \\
\hline - & 0 & 2 & 4 & 8 & 12 & 16 & 24 \\
\hline $\mathrm{N} \%$ & 0.9240 & - & - & - & - & - & 0.4690 \\
\hline
\end{tabular}

*Denotes significance (Alpha $=0.05)$ 


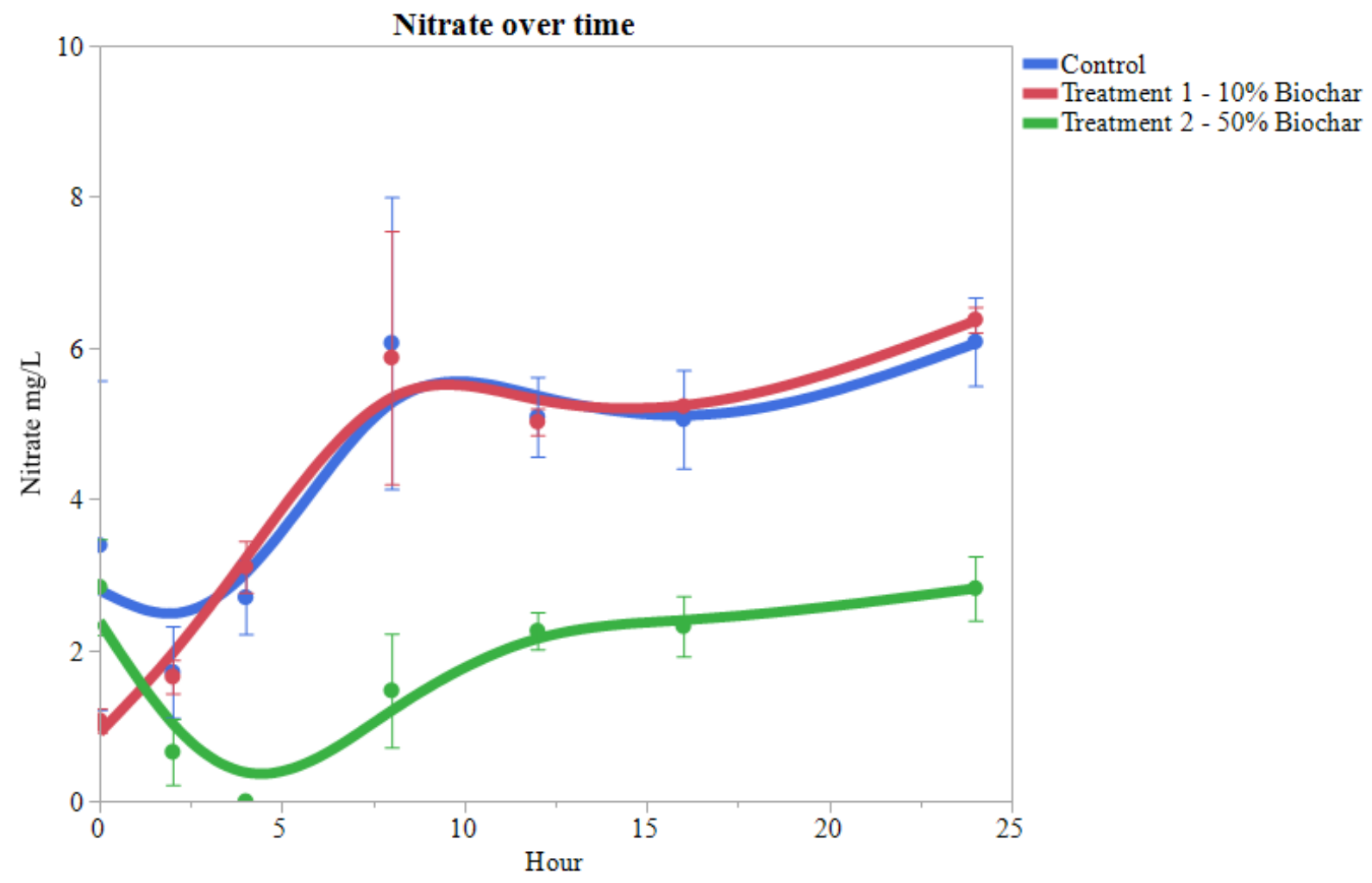

Figure 1. Nitrate over 24 hours for Batch Study. Error bars show standard errors of concentrations 


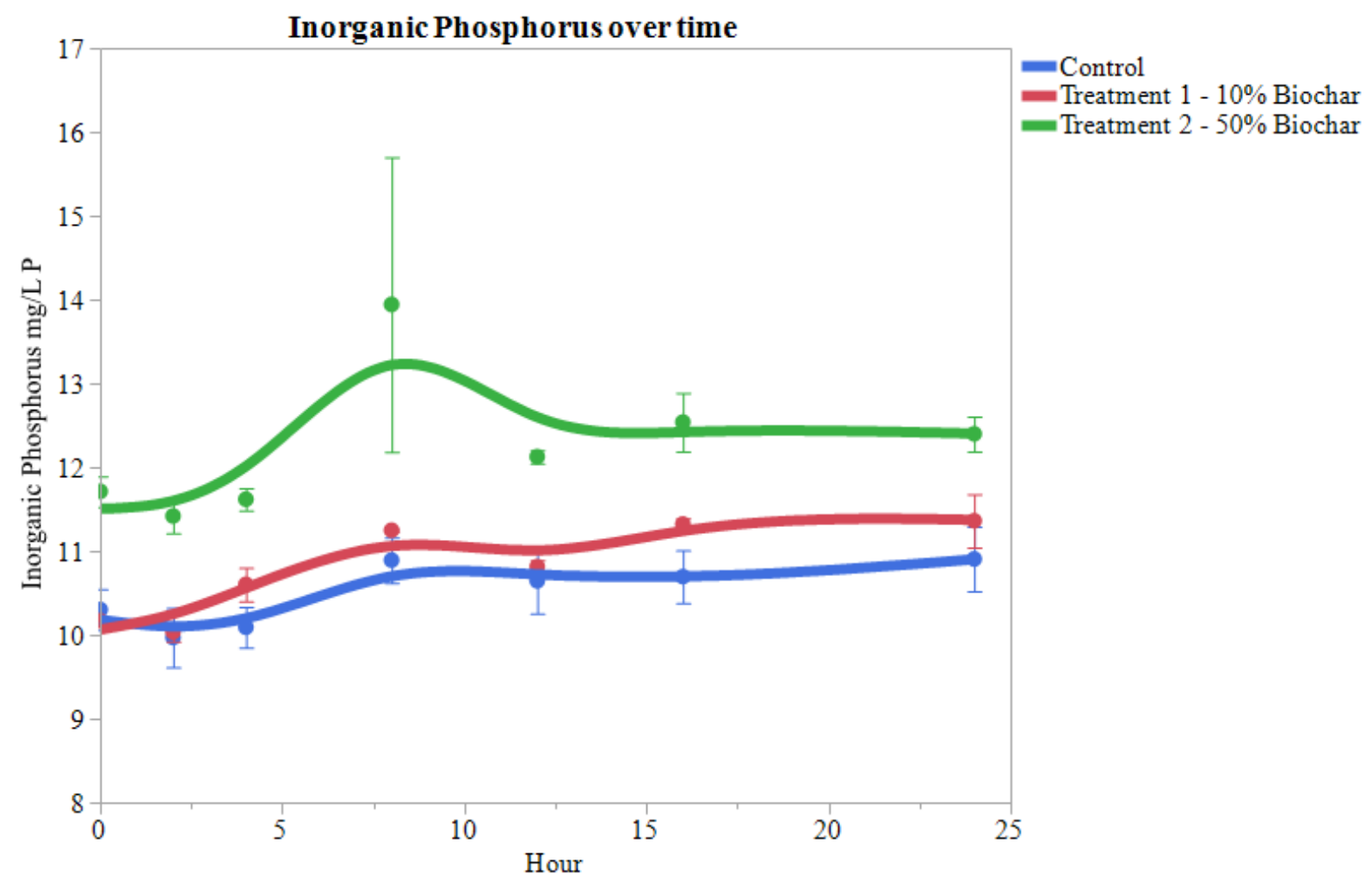

Figure 2. Inorganic phosphorus over 24 hours for Batch Study. Error bars show standard errors of concentrations 


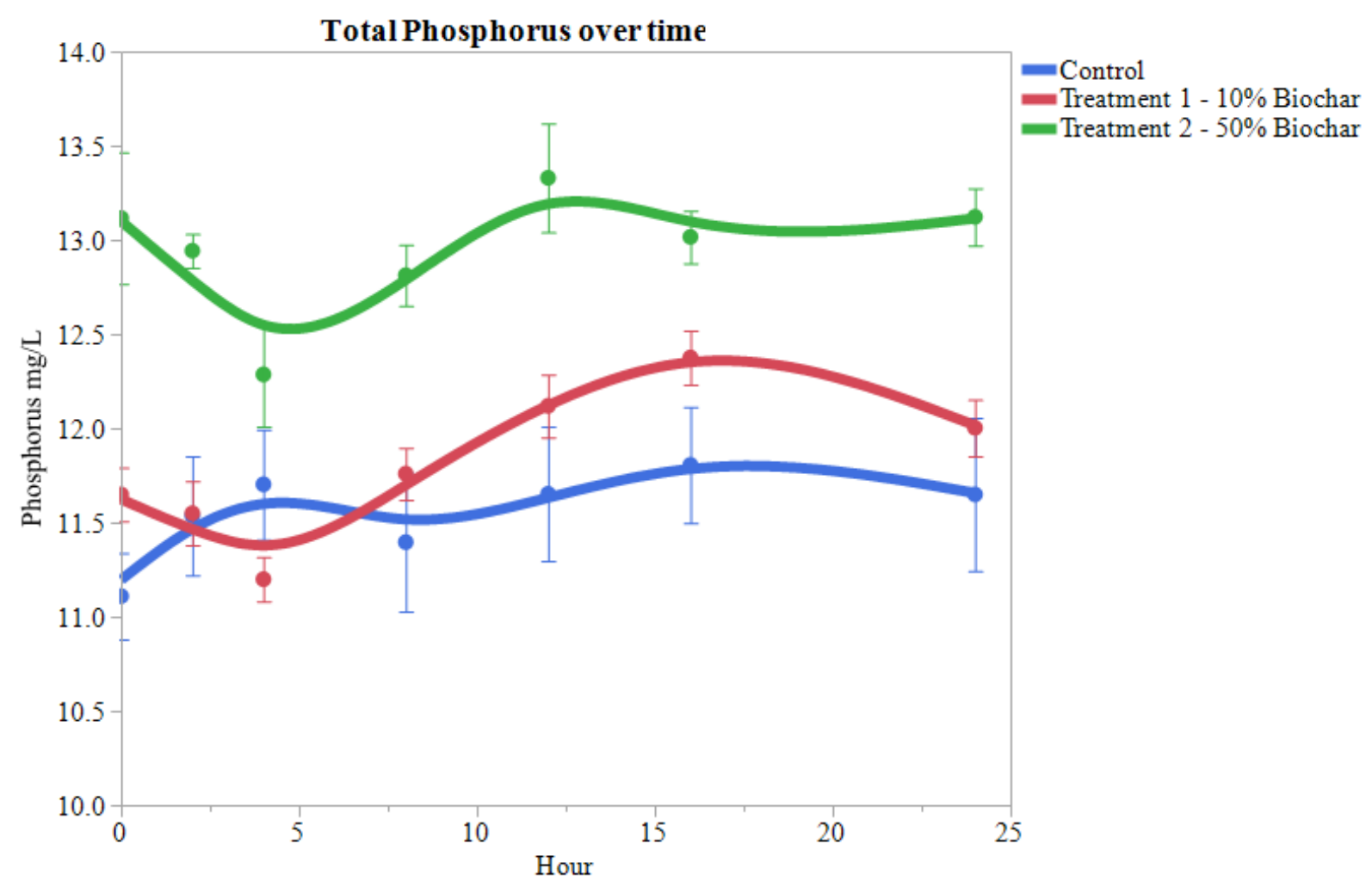

Figure 3. Total phosphorus over 24 hours for Batch Study. Error bars show standard errors of concentrations 


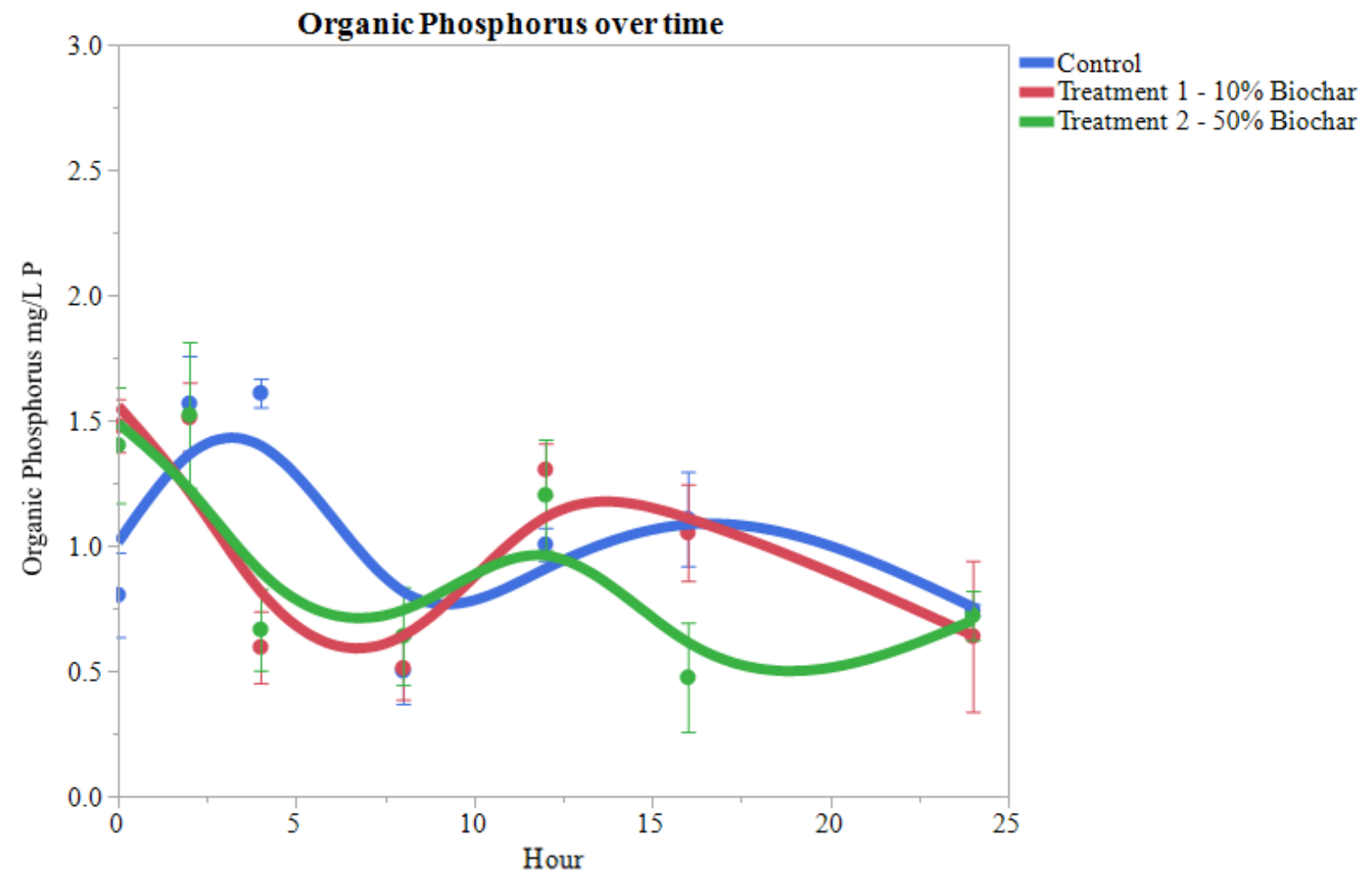

Figure 4. Organic phosphorus over 24 hours for Batch Study. Error bars show standard errors of concentrations 


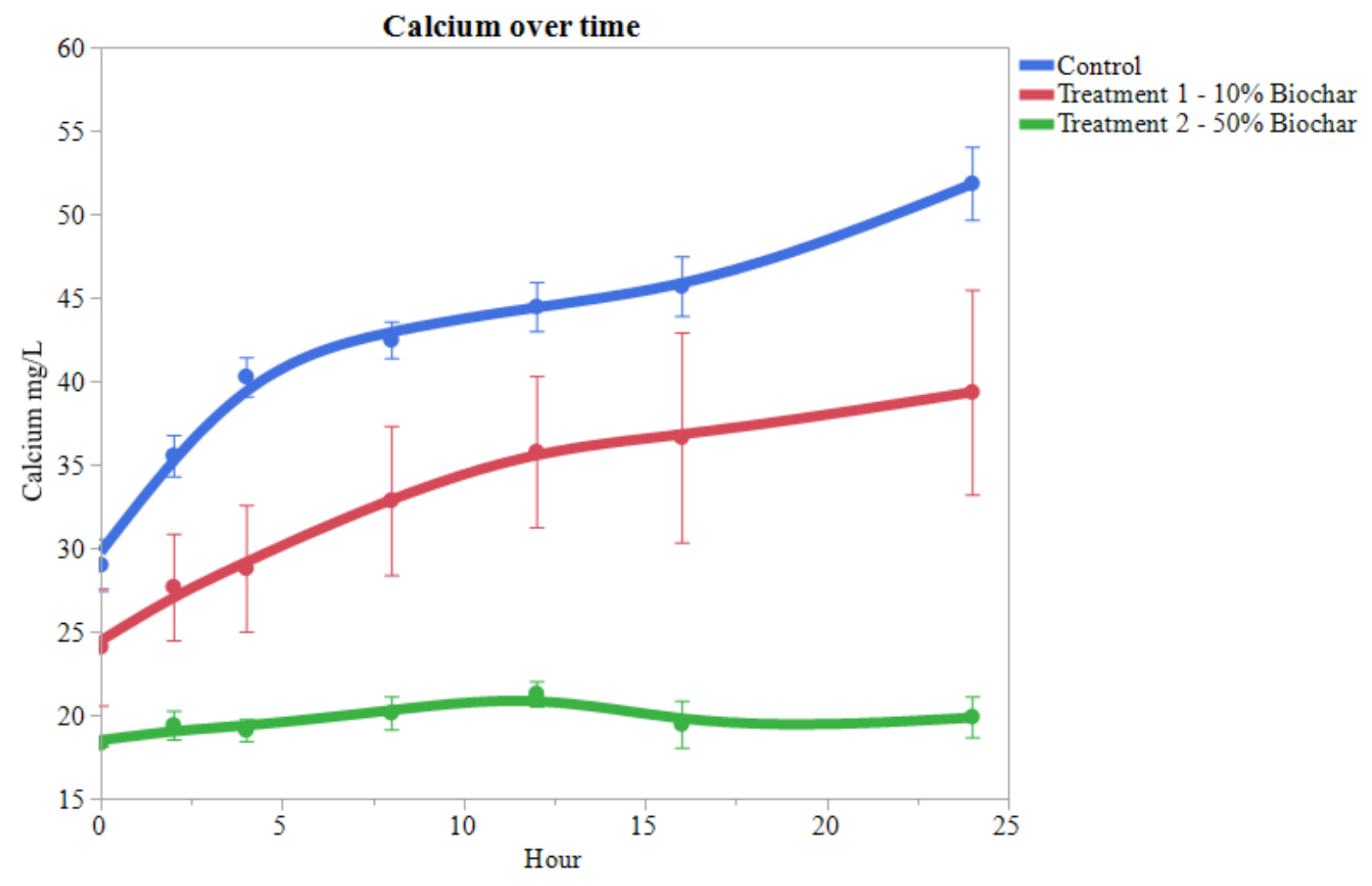

Figure 5. Calcium over 24 hours for Batch Study. Error bars show standard errors of concentrations 


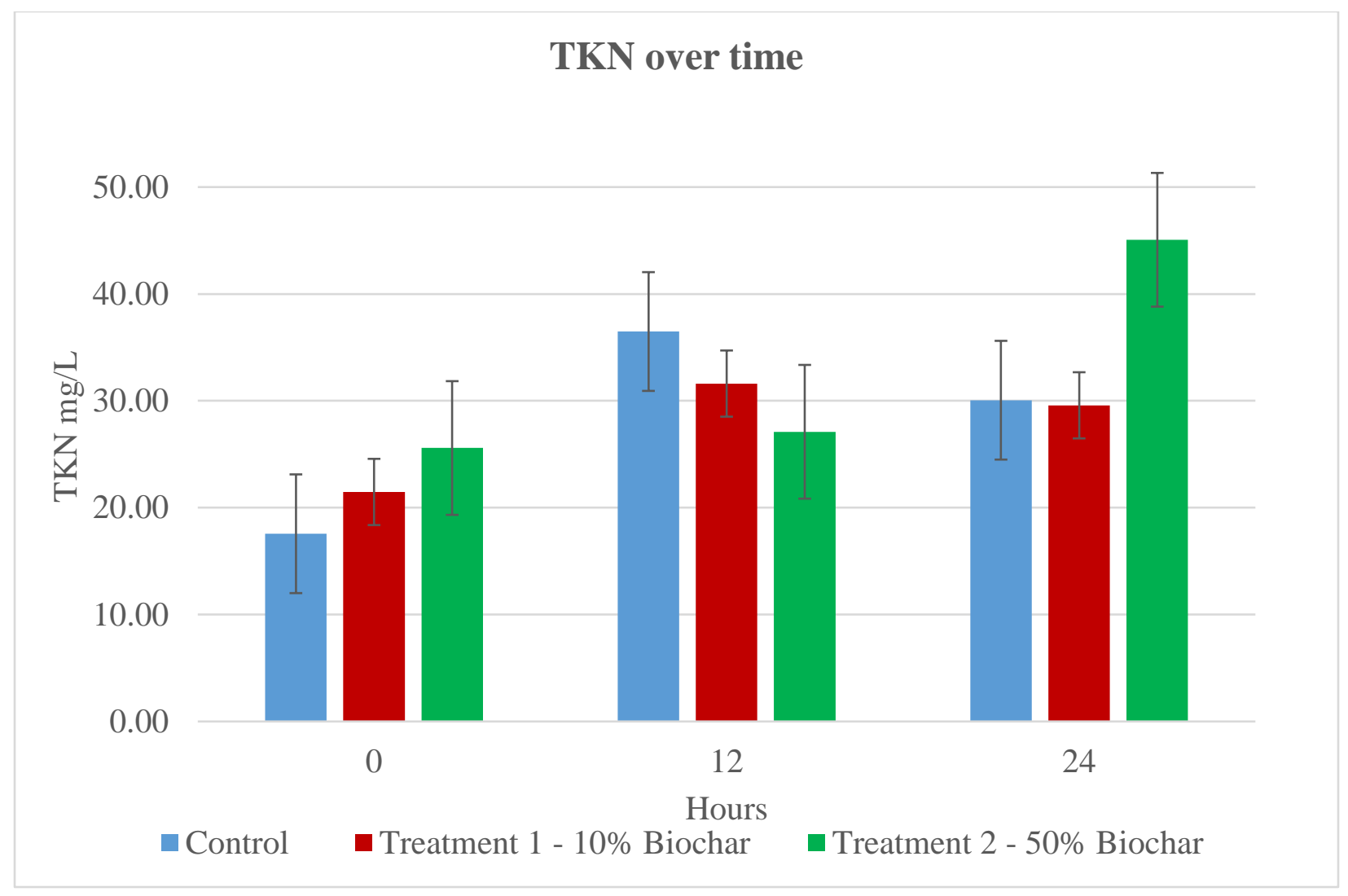

Figure 6. TKN values for woodchips at time: 0, 12, and 24 hours. Error bars show standard errors of concentrations 


\section{Appendices}

\section{Appendix 1: Preliminary Study: Assessment of experimental woodchip pad}

Objective: To characterize and monitor conditions of the WVU Animal Sciences

Research Farm experimental overwintering woodchip pad for $\mathrm{pH}$ and $\mathrm{EC}$ changes during normal weather conditions.

An initial onsite evaluation was performed on the WVU Animal Sciences Research Farm overwintering woodchip pad. During this time the pad was used as a loafing area for overwintering dairy cattle. The data was collected over a period of time to determine the variability in $\mathrm{pH}$ and $\mathrm{EC}$ that effluent waters may experience during different precipitation periods and manure loads. This data may also have inferences on microbial loads leaving the system, as more flow would equate more dilute or less microbes leaving the system which could influence the initial performance of a downstream bioreactor.

This data provides insight on site-specific values and also corresponds to values presented from other studies in terms of the $\mathrm{pH}$ from discharge waters from these sites. In terms of $\mathrm{pH}$ required for denitrifiers, this discharge falls under that range. A general trend based on the site data follows precipitation events. As runoff occurs in both cases, both $\mathrm{pH}$ (Figure A1-1) and EC (Figure A1-2) tended to increase possibly caused by a flushing of more materials from the site (Figure 1, Figure 2). It is important to note that during the period of $2 / 15-2 / 16$ a slight snow event occurred with freezing temperatures. As this melted, a spike can be seen in the data as runoff began to increase.

Assessment: Natural fluctuations within the system occurs depending on weather events, and due to flushing of materials. Overall, $\mathrm{pH}$ levels were determined to be adequate for 
denitrifying bacteria. While no nutrient values were taken at this time, future analysis showed discharge levels less than $10 \mathrm{mg} / \mathrm{L} \mathrm{NO}_{3}{ }^{-}$, further supporting the presence of bacteria on this site. 


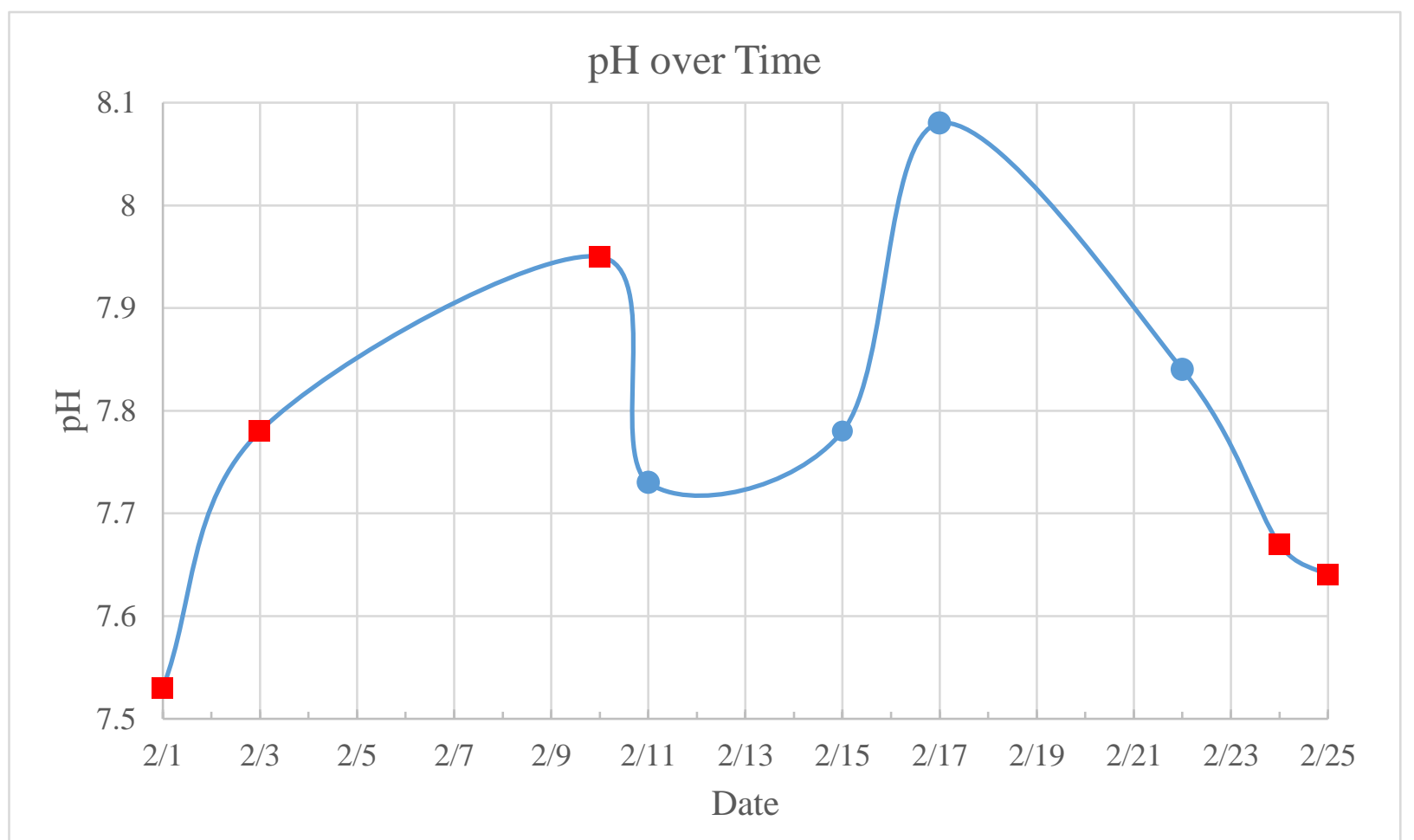

Figure A1-1. pH of farm effluent over time. Red squares denote rain events within 24 hours prior to sampling. 


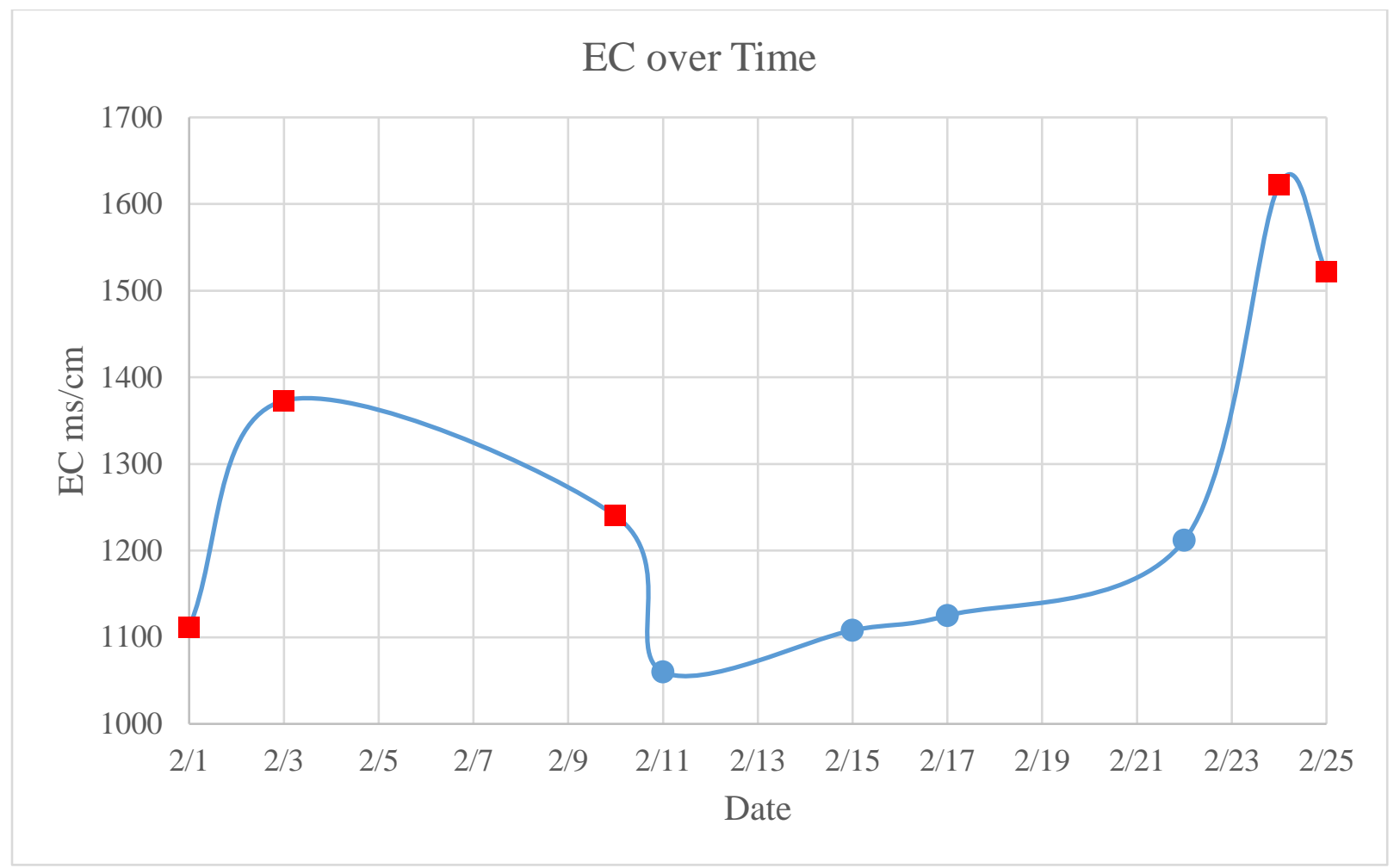

Figure A1-2. EC of farm effluent over time. Red squares denote rain event within 24 hours prior to sampling. 
Appendix 2: Preliminary Study: Woodchip and Biochar Characterization-Control Study

Objective: To characterize research material leachate for $\mathrm{pH}, \mathrm{EC}, \mathrm{NO}_{3}^{-}, \mathrm{PO}_{4}^{-3}$, and material solids for total carbon, nitrogen, sulfur, and $\mathrm{C} / \mathrm{N}$ ratio over a 24 hour period.

To initially assess and characterize the materials to be used in the project, a control run was performed. The evidence provided concluded some insight of the possible performance of the bioreactors used in the batch study, as well as the role of biochar.

Treatment set up consisted of a control of woodchips only and a treatment of woodchip and biochar. Treatments were done in triplicate. Six 2000ml glass beakers were set up on stir plates for the length of the experiment. 150g of the collected woodchips were placed each beaker. Three of the 6 beakers received a biochar addition of 5\% w/w (7.5g). After the addition of the media, 1,500 ml distilled, deionized water (DDIW) water was added to each container and allowed to spin on the stir plate uninterrupted. A 50ml sample was collected then filtered using a Fisher Scientific Q2 Quantitative Filter and analyzed for $\mathrm{pH}, \mathrm{EC}, \mathrm{NO}_{3}-, \mathrm{PO}_{4}^{-3}$, and a reading taken at $600 \mathrm{~nm}$ using the spectrometer to characterized the browning of the water associated with woodchips and their release of tannins which could inhibit bacterial growth. The rate of collection is as follows; For Hour 1 samples were taken every 10 minutes, Hour 2 sampled every 15 minutes, Hour 3-12 sampled time every 30 minutes, and Hour $12-24$ sampled at hour 12, 14, and 24 for a sample total of 15 samples per beaker. An initial and post experimental grab sample of the solid mixture was collected in duplicate and analyzed for total carbon, nitrogen, and $\mathrm{C} / \mathrm{N}$ ratio. Results are recorded as an average over the three replications.

No incubation or inoculation was done on any kind on the treatments, all collected data is from discharge solely from the treatment media. There were only slight differences among the media, with the main difference coming from inorganic P (Figure A2-1). Based off this data, the 
biochar may serve as a source rather than a sink of phosphorus in these systems. Another notable difference is the different $\mathrm{pH}$ values, biochar held a higher average $\mathrm{pH}$ for the length of the trial which may aid in providing an adequate and functional $\mathrm{pH}$ for the denitrifying community (Table A2-1). For the solid samples, overall there was minimal differences between initial and post values (Table A2-2). Nitrate over the length of the experiment showed an overall decrease (Figure A2-2). Since incubation was not performed during this experiment, this decrease may be due to the absorption of nitrate by the woodchips themselves, with an initial discharge. The $600 \mathrm{~nm}$ reading over time showed an increase in levels for the woodchip with biochar additions possibly related to the fines present in the biochar (Figure A2-3).

Assessment: Biochar additions increased solution $\mathrm{pH}$, however, it also increased the concentration of solution phosphorus. This may be due to the feedstock and nature of the biochar. Phosphorus interactions have not been well studied within these systems, mainly studies have focused on interactions within soils. Since no nutrient source was added, phosphorus from the material was allowed to leach out. This material is used for plant production, meaning it may have high initial nutrient levels. Biochars made from other feedstock may have much lower concentrations, which could result in phosphorus uptake instead of discharge. 
Table A2-1. Characterization of liquid samples

\begin{tabular}{lccccc}
\hline Sample & $\mathrm{pH}^{*}$ & $\mathrm{EC}(\mu \mathrm{S} / \mathrm{cm})^{*}$ & $\mathrm{NO}_{3}{ }^{-} \mathrm{mg} / \mathrm{L}^{*}$ & $600 \mathrm{~nm}^{*}$ & Inorganic $\mathrm{P} \mathrm{mg} / \mathrm{L}^{*}$ \\
\hline Woodchips & 4.59 & 88.42 & 1.24 & 0.01 & 0.54 \\
Woodchips and Biochar & 5.00 & 132.88 & 1.06 & 0.06 & 2.16 \\
DDIW & 5.82 & 3.76 & - & 0.0 & - \\
*Values denoted as an average over time & & & &
\end{tabular}


Table A2-2. Characterization of solid samples

\begin{tabular}{lccc}
\hline Sample & $\mathrm{C} \%$ & $\mathrm{~N} \%$ & $\mathrm{C} / \mathrm{N}$ ratio \\
\hline Initial-Woodchips & 45.9 & 0.20 & 225.9 \\
\hline Post-Woodchips & 48.1 & 0.24 & 204.2 \\
Post- Woodchips and Biochar & 48.1 & 0.24 & 201.7 \\
\hline
\end{tabular}




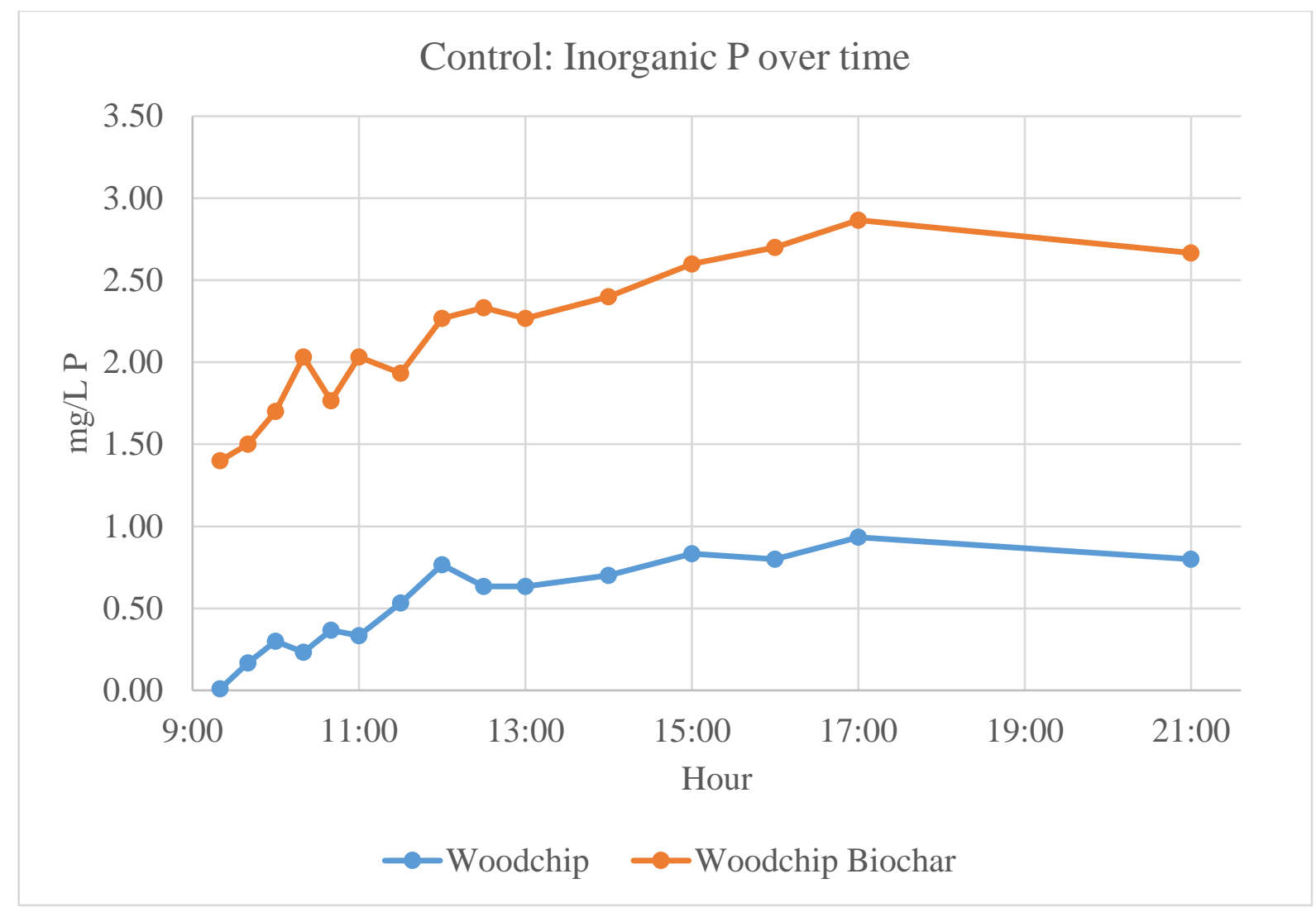

Figure A2-1 Inorganic phosphorus over time for the control experiment 


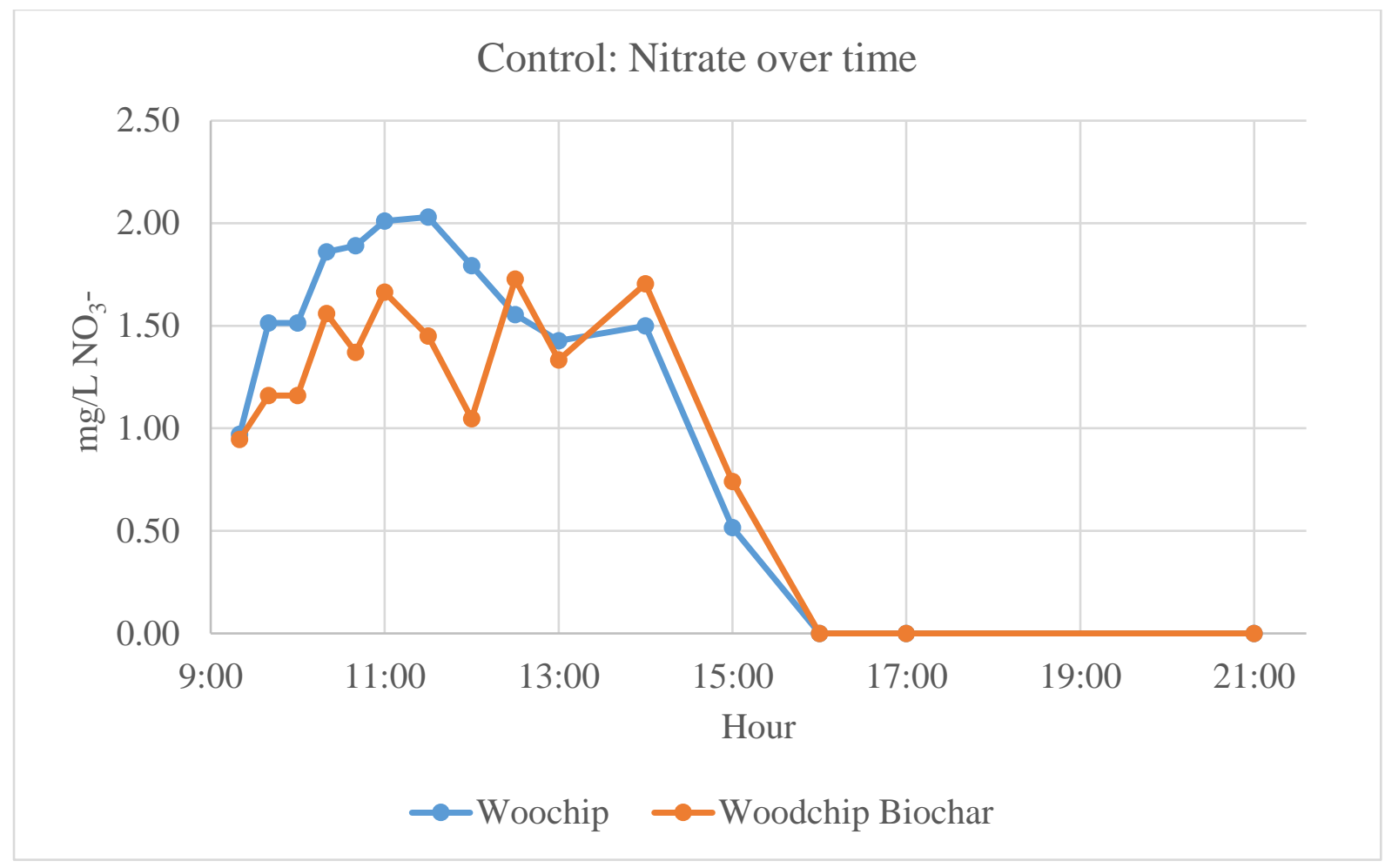

Figure A2-2. Nitrate over time for the control experiment 


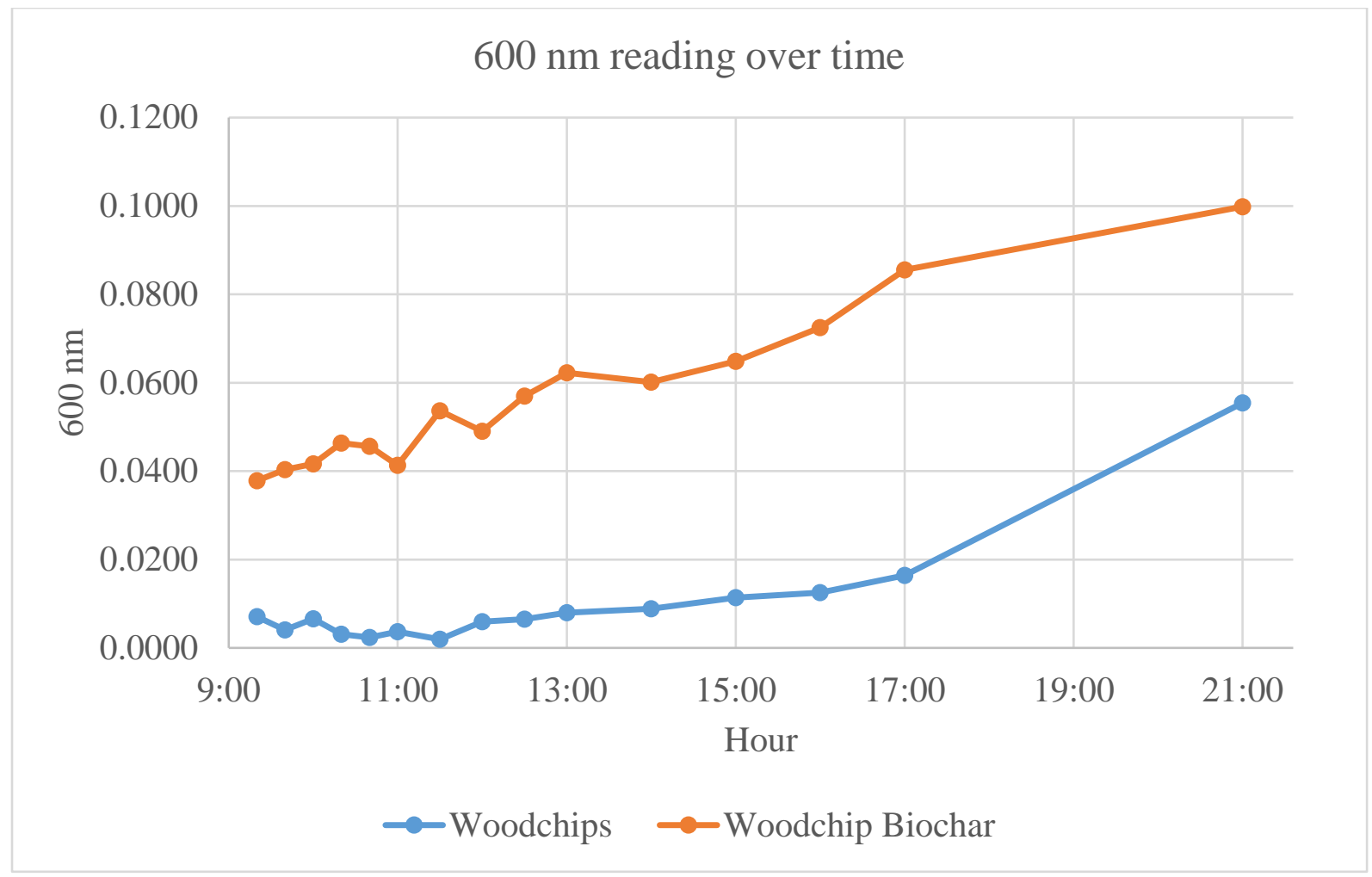

Figure A2-3. 600nm reading over time for the control experiment 


\section{Appendix 3: Preliminary Study: Biochar Characterization}

Objective: To characterize the leachate from the biochar material used for the studies, looking at $\mathrm{pH}, \mathrm{EC}$, inorganic phosphorus, and total phosphorus.

A follow up study looking at just the effects of biochar and phosphorus was done using a similar set up as the control study previously done. Treatments for this experiment consisted of a treatment of $20 \%(30 \mathrm{~g})$ and $50 \%(75 \mathrm{~g})$ of biochar. Woodchips were not used in this study. $1,500 \mathrm{ml}$ of a $10 \mathrm{mg} / \mathrm{L}$ phosphorus (potassium phosphate) solution was added to the jars and allowed to stir for 24 hours. The sampling regimen was the same as previously described. Again, no incubation was done, as this study just looked at the interaction of biochar in the presence of phosphorus. Overall, this study supported the previous data, that biochar may in fact be a source of phosphorus rather than a sink in these reactors. While there is a $\mathrm{pH}$ benefit, increasing or adding biochar is shown to increase total phosphorus amounts (Table A3-1).

Assessment: Similar to the previous study, again increases in $\mathrm{pH}$ and solution phosphorus was observed. This occurred even in the presence of a nutrient solution. This supports the idea that this feedstock has high initial nutrient concentration for plant growth. A nutrient poor biochar may better serve to decrease nutrient levels. Size may also factor into this, as larger biochar may be more beneficial than then smaller type used for the project. 
Table A3-1. Characterization of liquid samples

\begin{tabular}{lcccc}
\hline Sample & $\mathrm{pH}^{*}$ & $\mathrm{EC}(\mu \mathrm{S} / \mathrm{cm})^{*}$ & Inorganic P mg/L* & Total P mg/L* \\
\hline Phosphorus solution & 4.80 & 349 & 5.00 & 5.00 \\
Biochar (20\%) & 7.44 & 168.16 & 7.96 & 9.15 \\
Biochar (50\%) & 7.40 & 324.85 & 9.33 & 14.23 \\
*Values denoted as an average over time for treatments &
\end{tabular}

*Values denoted as an average over time for treatments 


\section{Appendix 4: Preliminary Study: Initial Bioreactor Trials}

Objective: This preliminary run served as an initial testing of design setup and focused on nitrate reductions.

An initial run was done testing the functionality and performance of the bench top bioreactors. The primary purpose of this trial was to determine if nitrate reductions could be observed and to monitor $\mathrm{pH}$ within the treatments. Ten, $3.8 \mathrm{~L}$ glass containers were filled with $300 \mathrm{~g}$ of woodchips. Treatment rates of $0 \%(0 \mathrm{~g}), 1 \%(3 \mathrm{~g}), 2.5 \%(7.5 \mathrm{~g}), 5 \%(15 \mathrm{~g})$, and $10 \%(30 \mathrm{~g})$ by weight of biochar were added to the jars and were done in duplicate. An incubation period of 72 hours was done with a pre-made manure slurry as a way to establish the needed microbial communities. After this period, the jars were drained then refilled with fresh slurry. The slurry was made by collecting fresh manure from the WVU Animal Science Research Farm, then mixed at a 5\% rate of manure solids to water. A $200 \mathrm{ml}$ sample was taken from these jars after the addition of the second slurry or hour 0 , then at 1, 4, 8, 12, 16, and 24 hours. Samples from both slurry mixtures were also collected for evaluation. All samples were evaluated for $\mathrm{pH}, \mathrm{EC}$, $\mathrm{NO}_{3}{ }^{-}$, and TKN. Results are recorded as an average over the treatment duplicates. Solution $\mathrm{pH}$ during the length of the trial average less than 7.0, while TKN was lower than the initial source, nitrate levels did not decrease over time as you would expect during denitrification (Table A4-1). There was an initial drop in nitrate for the treatments during the first hour, but the initial sample at hour 0 may have been higher due to the mixture of both slurry's within the jar, as not all of the incubation solution could be removed due to the jar design (Figure A4-1).

Assessment: Several issues occurred during this study. Overall nitrate levels did not decrease but increase over time. This may be due to the lack of denitrifying bacteria within the system. The $\mathrm{pH}$ level average over the sample time was lower than that preferred by the bacteria. 
There may have also been an issue with collecting the bacteria as incubation was done with manure collected from cattle, however, this manure did not reside in pasture longer than 48 hours before collection. The manure slurry also had some issues, due to the mixing and settling of solids, initial nutrient content from jar to jar varied as solids were not strained out and potentially caused clogging in some jars. For this reason, the design was changed over the next several studies to increase $\mathrm{pH}$, reduce clogging, and increase bacteria colonization. Another explanation could be nitrification within the jars, from possible pockets of oxygen present during the experiment. This would have led to nitrification or an increase in nitrate instead of a decrease associated with denitrification which cannot occur when oxygen is present. 
Table A4-1. Characterization of liquid samples

\begin{tabular}{ccccc}
\hline Sample/Biochar Rate & $\mathrm{pH}^{*}$ & $\mathrm{EC}(\mu \mathrm{S} / \mathrm{cm})^{*}$ & $\mathrm{TKN} \mathrm{mg} / \mathrm{L}^{*}$ & $\mathrm{NO}_{3}{ }^{-} \mathrm{mg} / \mathrm{L}^{1}$ \\
\hline $0 \%$ & 6.27 & 280.14 & 63.25 & 1.90 \\
$1 \%$ & 6.37 & 272.36 & 68.59 & 0.69 \\
$2.5 \%$ & 6.44 & 276.86 & 68.51 & 3.73 \\
$5 \%$ & 6.40 & 273.07 & 64.87 & 3.62 \\
$10 \%$ & 6.42 & 279.43 & 69.82 & 1.95 \\
Slurry & 7.05 & - & 89.45 & 3.02 \\
\hline
\end{tabular}

*Values denoted as an average between duplicates and over all time points for treatments

${ }^{1}$ Denotes change between initial and final value 


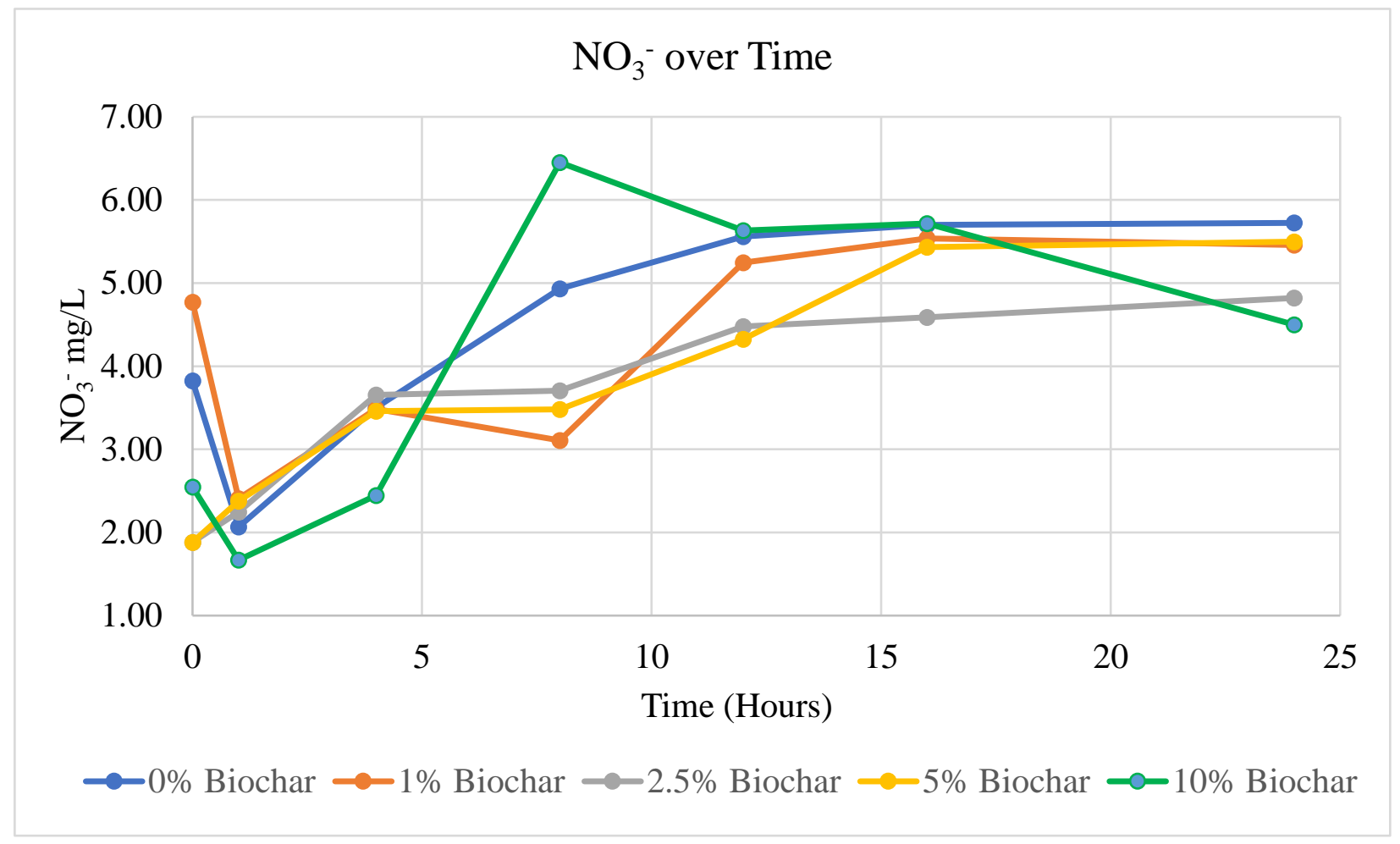

Figure A4-1. Nitrate levels for treatments over 24 hours. Values denoted as an average between duplicates. 


\section{Appendix 5: Preliminary Study: Limestone Characterization}

Objective: An addition of limestone in order to control $\mathrm{pH}$ within the reactor was done, with $\mathrm{pH}, \mathrm{EC}$, and $\mathrm{NO}_{3}$ - data collected on the leachate to determine any nutrient leaching and $\mathrm{pH}$ changes from this addition.

After the initial run, several changes were made to the design. The first change was the addition of limestone chips and powder to the jars. This served to increase the $\mathrm{pH}$ to the optimal range needed for denitrification. Treatments that were selected were, 100g limestone chips and

powder, 200g of limestone chips and powder, 100g of limestone chips and powder with 200g of woodchips, and $200 \mathrm{~g}$ of limestone chips and powder with $200 \mathrm{~g}$ of woodchips. $2000 \mathrm{ml}$ beakers were used and placed on stir plates and allowed to stir uninterrupted the length of the study. An addition of $1000 \mathrm{ml}$ was added to each jar with a 100ml sample taken at time point $0,2,4,8,24$, and 48 hours. This sample was immediately filtered using a Fisher Scientific Q2 Quantitative Filter then analyzed for $\mathrm{pH}, \mathrm{EC}$, and $\mathrm{NO}_{3}^{-}$(Table 7).

Assessment: The addition of limestone was shown to increase the $\mathrm{pH}$ to an acceptable level, well within the range needed for denitrifying bacteria (Table A5-1). No nitrate was shown to be leached from the limestone, and it had no effect on nitrate leaching of the woodchips. Due to the design of the jars, 200g of limestone was selected for use, since not all of the initial solution can be removed from the jars, increasing the limestone increased its space in the jar, decreasing the amount of interference between solutions. 
Table A5-1. Data for limestone characterization study

\begin{tabular}{lccc}
\hline Sample & $\mathrm{pH}^{*}$ & $\mathrm{EC}(\mu \mathrm{S} / \mathrm{cm})^{*}$ & $\mathrm{NO}_{3}{ }^{-} \mathrm{mg} / \mathrm{L}^{*}$ \\
\hline 100g Limestone & 7.53 & 66.58 & 0.00 \\
200g Limestone & 7.54 & 49.35 & 0.00 \\
100g Limestone + 200g Woodchips & 7.22 & 341.25 & 6.00 \\
200g Limestone + 200g Woodchips & 7.25 & 324.10 & 5.86 \\
\hline *Values denoted as an average over time for treatments & &
\end{tabular}




\section{Appendix 6: Preliminary Study: Microbial Study}

Objective: This study focused indirectly on the microbial populations, involving a change in incubation source in order to determine if denitrification was possible using runoff from the WVU Animal Sciences Research Farm overwintering experimental chip pad.

Since the main study was performed in a laboratory setting and not in a natural setting, the introduction and incubation of the needed denitrifying microbial community was critical. The previous method of creating and incubating with the manure slurry was inadequate, and from the data shown did not allow the right environment for denitrifiers to colonize or inhabit the jars. The combat this, runoff samples were taken from the WVU Animal Sciences Research Farm experimental overwintering woodchip pad as its design is similar to that of a bioreactor and may prove to be a sufficient source of natural microbes needed to inoculate the laboratory study. The purpose of this study was to look at this runoff as a potential source of microbes needed for the proper function of the bioreactors. Treatments consisted of 3 different incubation times, Treatment 1: 72 hour incubation, Treatment 2: 24 hour incubation, Treatment 3:1 hour incubation. Jars were filled with $200 \mathrm{~g}$ of limestone chips and powder as well as $200 \mathrm{~g}$ of woodchips. For the initial incubation, $2 \mathrm{~L}$ of freshly collected runoff was collected and placed in the jars. Jars were then wrapped in foil to prevent interference from light and allowed to sit. After the set incubation period the liquid was drained then refilled with an addition $2 \mathrm{~L}$ of runoff. $150 \mathrm{ml}$ samples were collected at time points $0,2,4,8,12,24$, and 48 hours. Samples were filtered with Fisher Scientific Q2 Quantitative Filters then stored at $0^{\circ} \mathrm{C}$ until analysis of $\mathrm{NO}_{3}{ }^{-}$ could be determined. Results are recorded as an average over treatment duplicates.

Based off the data collected, the runoff did show an effect on the microbial population and its ability to colonize the jars. Reductions were observed in the 72 hour incubation and the 
24 hour incubation (Figure A6-1). Between these treatments however, there was no significant difference found using a t-test for paired two sample means (Table A6-1). This data supports a 72 hour incubation time as reported by other studies as a sufficient time for microbial and for the use of the runoff as a source (Bock, 2015).

Assessment: This study shows the applicability of using collected runoff as an incubation source. Consistent with other studies, a 72 hour incubation period resulted in almost complete reduction of nitrates in the solution. The microbial load from the chip pad appears to be much higher than just the manure. This may be due to the setup of the pad, as it serves to decrease nitrates from percolated waste water, meaning colonization within the pad has already occurred. Sampling was taken after a storm event which may have flushed these colonies out and were collected and introduced to the study system. Flow during the sampling was low, so the bacterial content may not have been as dilute as a high flow event. 


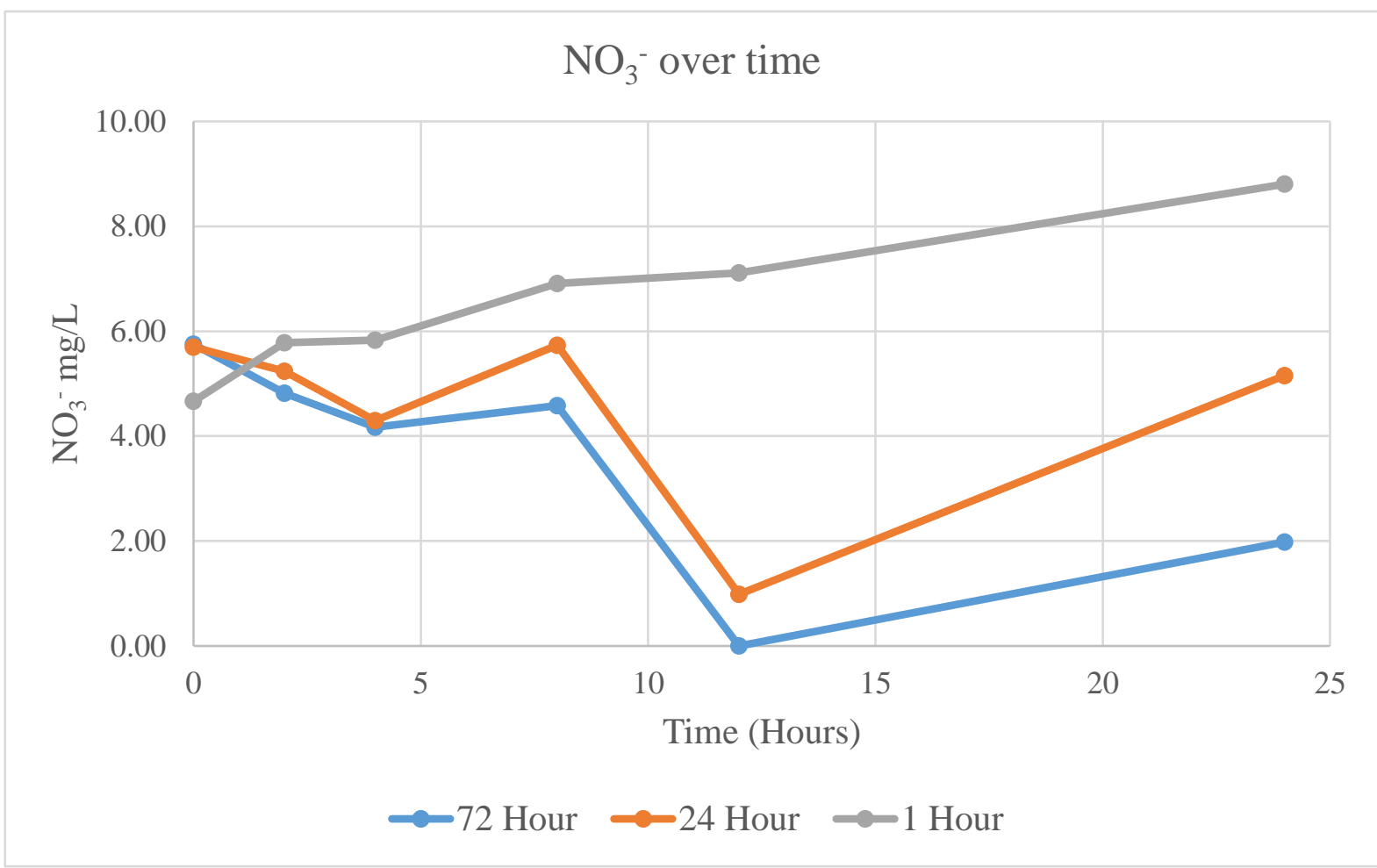

Figure A6-1. Nitrate levels for treatments over 24 hours. Values dentated as an average between duplicates. 
Table A6-1. t-Test Paired Two Sample for Means

72 hour incubation $\quad 24$ hour incubation

\begin{tabular}{lcc}
\hline Mean & 3.55 & 4.52 \\
Variance & 4.59 & 3.27 \\
Df & 5 & - \\
$\mathrm{P}(\mathrm{T}<=\mathrm{t})$ one-tail & 0.05 & - \\
$\mathrm{P}(\mathrm{T}<=\mathrm{t})$ two-tail & 0.10 & - \\
\hline
\end{tabular}

*Alpha set at 0.05 
Appendix 7: Preliminary Study: Incubation times

Objective: The focus of this study was to evaluate design changes as well as additional work on incubation times using a new nutrient source method.

One last study was performed testing the use of the runoff and a new method for making the manure effluent. This new process, similar to compost tea, was evaluated over 4 different treatments. Each container (minus treatment 4) contained 200g of limestone powder and chips followed by 200g of woodchips. Runoff collected from the Animal Sciences Research Farm overwintering chip pad was used for incubation for a set amount of time depending on the treatment. After this period, jars were drained and refilled with $2 \mathrm{~L}$ of the manure tea solution. Treatments were as follows, Treatment 1: 72 hour incubation hold, Treatment 2: 24 hour incubation hold, Treatment 3: 24 hour incubation hold using refrigerated runoff (RF), Treatment 4: 72 hour incubation hold without limestone added (NL). $150 \mathrm{ml}$ samples were collected at time points 0, 2, 4, 8, 12, and 24. Samples were filtered with Fisher Scientific Q2 Quantitative Filters then stored at $0^{\circ} \mathrm{C}$ until analysis of $\mathrm{NO}_{3}{ }^{-}$could be determined. For liquid samples $\mathrm{pH}$, total TKN, inorganic phosphorus, and total phosphorus were determined. Post treatment data on the material solids were also determined for total carbon, nitrogen, sulfur, and $\mathrm{C} / \mathrm{N}$ ratio. Results are recorded as an average over the treatment duplicates. Similar to the previous study, treatments experienced a reduction in nitrate levels, (Figure A7-1).

Assessment: This final study was used as a preliminary look at design changes and nutrient source differences. Nitrate reductions occur within treatments, again supporting the use of the runoff as a source. 


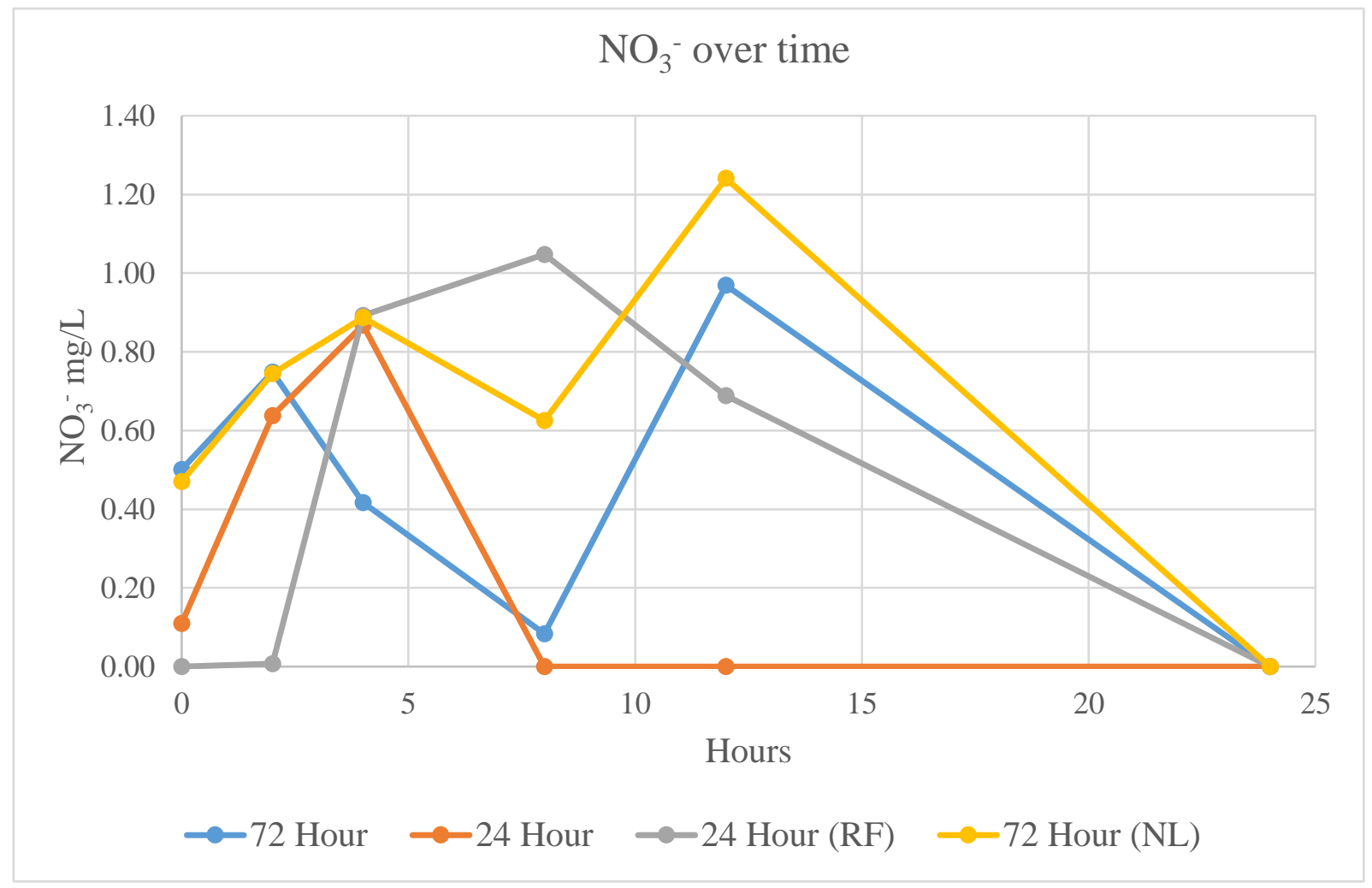

Figure A7-1. Nitrate levels for treatments over 24 hours. Values denoted as an average between duplicates. 


\section{Appendix 8: Woodchip analysis}

For the woodchips, the N\% was not significant by treatment or by time (Table 6 . Table 7). The average initial N\% across treatments was $0.59 \%$, and $.48 \%$ for the final (Figure 7). For C\% in the woodchips, there was a significant decrease with time, from $42.98 \%$ toe.60\% (Figure 8). $\mathrm{C} / \mathrm{N}$ was not significant (Table 5). Initial values for the treatments were 73.03 while the final averaged 74.14 (Figure 9).

For $\mathrm{N} \%$ and $\mathrm{C} \%$ as well as the $\mathrm{C} / \mathrm{N}$ ratio, time may have an influence, as the longer the media is allowed to decompose, these values would change over time. Since there was a significance over time for the $\mathrm{C} \%$, this carbon may have been leached from the woodchips or used a carbon source by possible microorganism within the reactors. However, in this case the reported significant difference may have been a result of different sampling and analysis methods used. For both the initial and final analysis, a grab sample of the woodchips were air dried then analyzed using an elemental analyzer (Elementar). However, this may have created a discrepancy with the data as samples may not have been fully dried meaning some liquid could have accounted for the reported values and there may have been some bias in selection as only chips that were small enough in size could be analyzed due to the restriction in the sample holder for the elemental analyzer. For this reason, this data may not be entirely representative of the experiment and should be taken under consideration for future work or for interpretation of the data. 


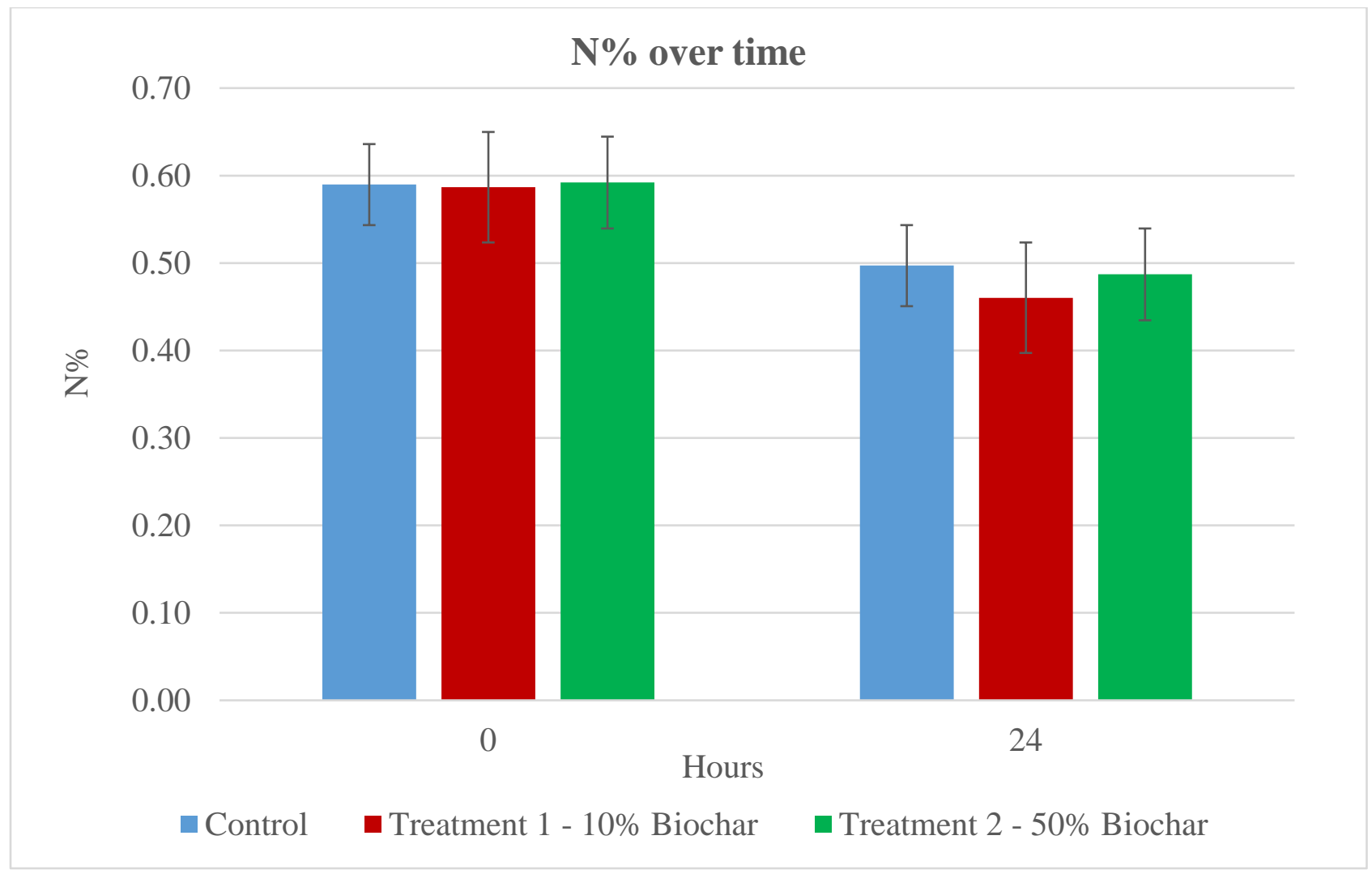

Figure A8-1. N\% for woodchips at time: 0 and 24 hours. Error bars show standard errors of concentrations 


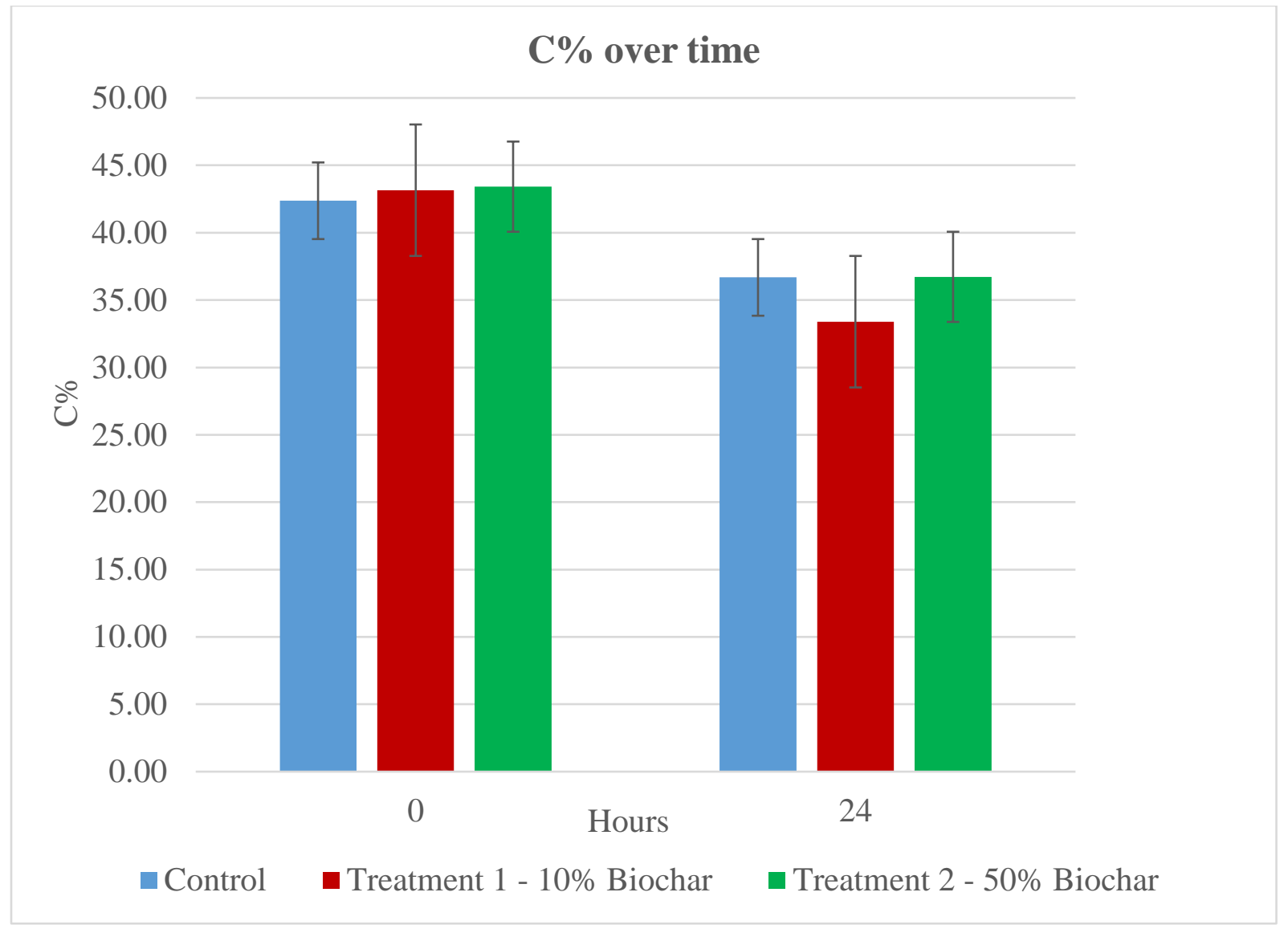

Figure A8-2. C\% for woodchips at time: 0 and 24 hours. Error bars show standard errors of concentrations 


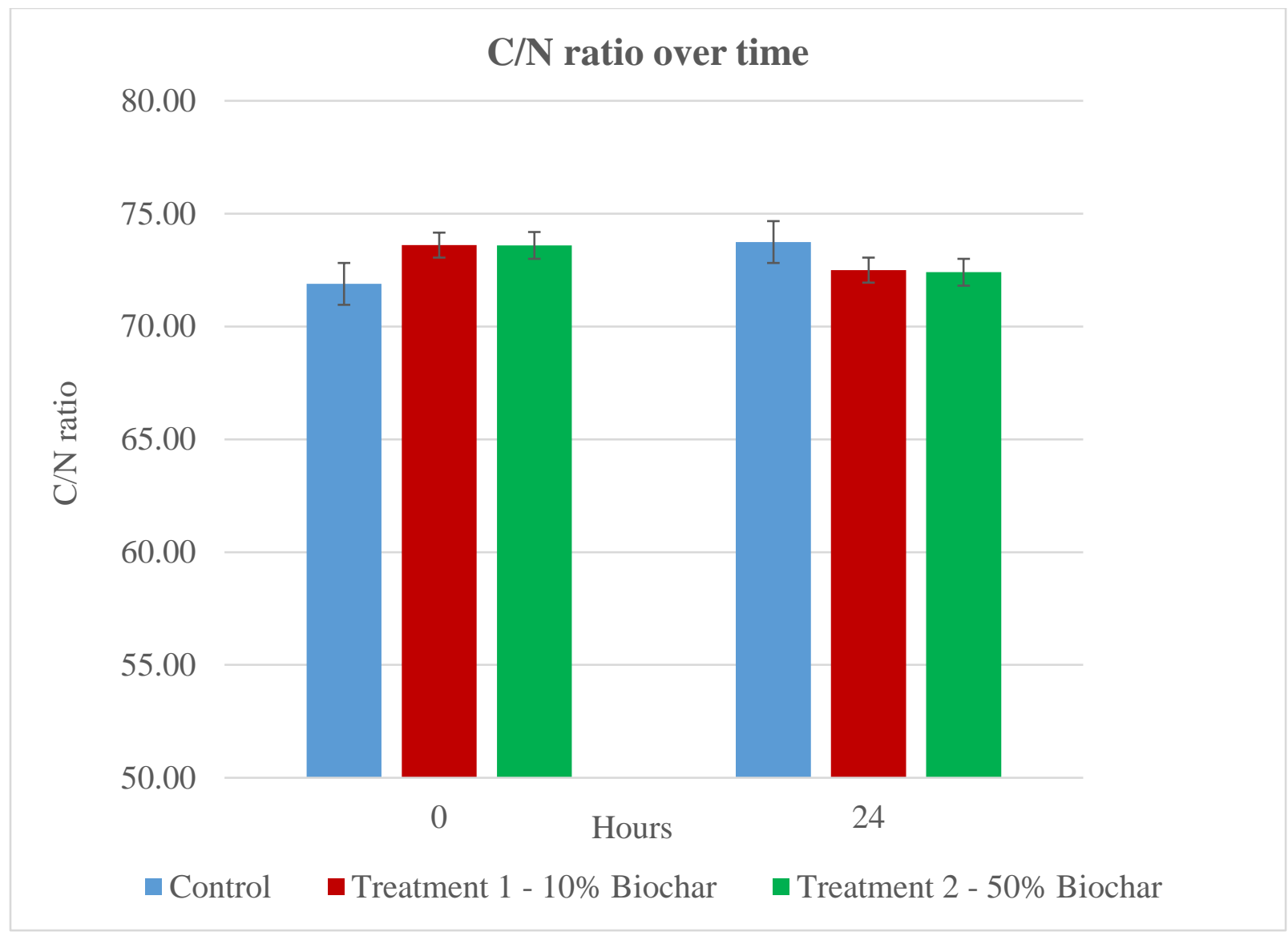

Figure A8-3. C/N ratio for woodchips at time: 0 and 24 hours. Error bars show standard errors of concentrations 